\title{
A continuous approximation model for the optimal design of public bike- sharing systems
}

\begin{abstract}
During the last decade, public bike-sharing systems have gained momentum and popularity. Many cities worldwide have put their trust in bike-sharing to promote bicycle use and move towards more sustainable mobility. This paper presents a parsimonious model from which to derive the optimal strategical design variables for bike-sharing systems (i.e. the number of bicycles, the number of stations and the required intensity of rebalancing operations). This requires an integrated view of the system, allowing the optimization of the trade-off between the costs incurred by the operating agency and the level of service offered to users. The approach is based on the modelling technique of continuous approximations, which requires strong simplifications but allows obtaining very clear trade-offs and insights. The model has been validated using data from Bicing in Barcelona, and the results prove, for example, the existence of economies of scale in bike-sharing systems. Also, station-based and free-floating system configurations are compared, showing that free-floating systems achieve a better average level of service for the same agency costs. In spite of this, the performance of free-floating systems will tend to deteriorate in the absence of a strong regulation. Furthermore, if electrical bikes are used, results show that battery recharging will not imply an active restriction in station-based configurations. In conclusion, the proposed modeling approach represents a tool for strategic design in the planning phase and provides a better understanding of bike-sharing systems.
\end{abstract}

Keywords: Bike-sharing, electric bike, facility location problem, rebalancing, optimization, continuous approximation, Bicing-Barcelona.

\section{Introduction to public bike-sharing systems}

Cities around the world envisage huge potential in cycling as a sustainable alternative to motorized individual mobility. The bicycle, as an urban transportation mode, accounts for a marginal modal share in many cities, while most of the urban trips could be done efficiently, in terms of time and costs, by cycling [Heinen el al. (2010)]. In such contexts, cycling could reduce motorized traffic and curtail pollutant emissions [Cao and Shen (2019)], promoting an environmentally sustainable and socially equitable transportation system, together with a healthier way of life [Jain and Tiwari (2016)].

Public bike-sharing programs stand out as one of the most ambitious initiatives taken by transportation authorities to promote cycling in cities. The bike-sharing concept is simple: take the bike for your trip and leave it behind for others when finished. Benefits for the user are multiple, including the release of all the burdens of ownership (i.e. investment, maintenance, storage, etc.) and the liberty and flexibility of one-way trips, not worrying about the bicycle once at the destination. Bike-sharing also provides a convenient alternative to walking for the first- and last-mile segments in multimodal trips [Lu et al. (2018)]. Pioneer implementations (e.g. White Bikes program in Amsterdam, The Netherlands (1965); Vélos Jaunes in La Rochelle, France (1974); Green Bike Scheme in Cambridge, UK (1993); or Bycyklen in Copenhagen, Denmark (1995)) allowed understanding that in order to reduce the exposure to theft and vandalism, both the user and the bike needed to be clearly identified. This, together with technological progress, gave rise to the currently most accepted framework of public bikesharing systems, based on bicycle docking at stations and electronic membership cards (known as $3^{\text {rd }}$ generation or station-based systems; see DeMaio (2009) or Shaheen et al. (2010) for an extensive review of the past, present and future of bike-sharing programs). In this type of systems, it is only at stations where members can pick-up or return bicycles. Implementations frequently referred to are Wuhan $(90,000$ bikes) or Hangzhou $(78,000)$, being the largest station-based systems in the world, and also Paris Velib (20,600), Barcelona Bicing $(6,000)$, or Montreal Bixi $(5,200)$. More recently, the introduction of GPS devices and advanced locks in shared bikes entailed new opportunities for the original concept of free-floating bike-sharing (i.e. station-less). Since 2015, free-floating initiatives have appeared around the world, and with special intensity in China. For example, Mobike and $O f o$, the two largest operators in China, rolled out 280,000 shared bikes in Shanghai and 200,000 in Beijing as of June 2017; by the end of 2017, these fleets had raised to 2.35 and 1.5 million respectively with a total of 15 operating companies. This explosive growth implied that globally, 150 Chinese cities were served by freefloating systems in 2017, with an intense competition between over thirty suppliers and more than 80 million 
1 registered users [Wang et al. (2019)]. Outside China, free-floating initiatives have been much more restrained, 2 including SocialBicycles (SoBi) mainly across the USA, or Call-a-bike in Germany [Reiss and Bogenberger 3 (2016)]. In these free-floating systems (which represent the $4^{\text {th }}$ generation of the bike-sharing concept), bikes are 4 spread out over a clearly limited service region. Bikes can be locked to an ordinary bicycle rack (or to any solid integrated into the bikes, which are equipped with a built-in GSM communication module allowing reservations to be made through a mobile app. Currently, bikes are locked/unlocked by scanning the QR code printed on the bike, which replaces the outdated built-in keypads and membership PINs. Also, bicycles generally have an integrated GPS device to prevent theft and allowing real-time tracking of the bicycle. In comparison with stationbased systems, free-floating configurations may save on the start-up cost by eliminating the cost of constructing stations, especially if the technological bike upgrades do not imply a significant extra-cost. Also, free-floating systems become more convenient for users because of shorter access distances, especially at the destination, but also at the origin if bikes are somehow uniformly distributed throughout the service region. From the user perspective, free-floating also eliminates the worries about the shortage of a vacant spot at the destination station. In spite of all these benefits, the lack of stations may also create problems, like bicycles clogging pedestrian walkways and overflowing into residential neighborhoods, thus disturbing residents. In fact, these problems have already appeared in the huge Chinese implementations, where authorities are debating and starting to implement new regulations for such systems [Wang et al. (2019)]. Regulation, together with the slowdown in the increase of the number of registered users in China is causing the collapse of some operating companies and is forcing others to withdraw the market. By April 2018, the number of operating companies in China decreased from 30 to 17. Despite this consolidation phase of the free-floating market, the current momentum of bike-sharing systems is a reality. Today, there are 1,975 cities around the world operating bike-sharing schemes, with approximately 15 million bikes in use [Bike-sharing World Map (2019)].

Electrical bike-sharing programs are not experiencing the same success yet. While bike-sharing programs are growing in most large cities around the world, electric-bikes are only used in small pilots, which generally do not become large-scale implementations. BiciMAD, the bike-sharing system in Madrid (Spain), is possibly the only exception, with 2,000 e-bikes and 165 stations. This situation is probably due to the higher investment costs of e-bikes and charging docks at stations, together with a shorter tradition of electrical bike technology. In spite of this, electrical bikes might have potential for improving the efficiency of bike-sharing systems, not only because users exhibit a higher willingness to use electric bikes [Martínez et al. (2012)], but also because the demand asymmetry towards down-sloping trips could be reduced, especially in hilly cities, alleviating the need for artificial rebalancing of the system.

Despite the popularization of the bike-sharing concept during the last decade, the system design is not free of difficulties. The main operational problem is the system's imbalance, caused by random and asymmetric demands (i.e. variable requests vs returns at different zones / stations). This gives rise to situations in which there are no available bicycles in a particular zone / station, while others are jam-packed. This last situation is more problematic in station-based systems because the user faces the impossibility of returning the bike in already full stations. System imbalance is addressed in the operating phase by artificially rebalancing bicycles among stations (or distribution zones, in case of free-floating systems). In addition to this, in the planning phase, the number, location and size of stations or distribution zones, and the size of the bicycle fleet, are critical decisions that affect rebalancing operations and steer the success of the implementation.

Optimal system design, in terms of the selection of the previous decision variables, should respond to the optimization of the trade-off between users' and operating agencies' costs. On the one hand, from the users' perspective, the service level is defined by the availability and accessibility of bicycles (i.e. in terms of the access distance), both at the origin and destination of the trip. This includes the ease of bicycle return. In general, the level of service increases with the number of bikes and with the number and size of stations. On the other hand, operating agencies aim to limit the investment and maintenance costs of bikes and stations, and the operational 
1 costs of bike repositioning within the system. The viability of a system depends on the ability to provide a 2 reasonably good level of service while keeping costs affordable. to give only general qualitative recommendations for the strategic system design [García-Palomares et al. (2012)]. Take as an example the Spanish methodological guide [IDAE (2007)]. In this context, new designs tend to be based on previous experience from other implementations, and trial and error. Bad system design implies long access times and high probabilities of full / empty stations, discouraging the demand for the system, or excessive operating costs. In both scenarios the system is condemned to failure.

In order to improve the decision-making process in the planning and design of public bike-sharing systems, it is needed a simple and quantitative optimization framework accounting for the main costs and existing tradeoffs. The present paper proposes a strategic design methodology for bike-sharing systems based on continuous approximations (CA). The method provides the optimal system design, in terms of the number of stations, total parking slots, size of the bicycle fleet and required repositioning level, from where to anticipate agency costs and the level of service offered. The CA approach requires simplification of the system by considering all variables as continuous. This allows analytical modeling of the system structure, unveiling the main insights and tradeoffs, which makes this approach suitable for planning purposes.

The structure of the remainder of the paper is as follows: the next section, Section 2, summarizes previous research on vehicle-sharing systems and justifies the proposed macroscopic modeling approach. Section 3 presents, in detail, the model formulation. Next, in Section 4, the Barcelona's Bicing system is selected as a case study. The analysis of the Bicing system includes the parameter estimation, the validation of the model and the optimization results. In addition, a sensitivity analysis is performed in order to generalize the obtained results. Finally, the paper ends with the conclusions section, acknowledgments and reference list.

\section{Literature review and modelling framework}

Bike-sharing systems have attracted increasing attention from the scientific community in the last years. While it was rather difficult to find any specific research work on bike-sharing before 2010 [Martínez et al. (2012)], today there is a vast amount of scientific literature dealing with this topic. Most of the methodological research appeared as an answer to the problems encountered by operating agencies running the bike-sharing systems implemented a few years earlier. The main operational problem is the fleet imbalance, and many research studies face this problem from the operations research perspective. Many times, this consists of defining the optimal routes and repositioning movements that light trucks should perform in order to rebalance the system with minimum cost. A number of studies address the static case, where the system is considered closed and the desired (i.e. the balanced) state is fixed (see [Alvarez-Valdes et al. (2016), Benchimol et al. (2011); Chemla et al. (2013); Dell'Amico et al. (2014); Li et al. (2016a); Raviv et al. (2013)] for station-based configurations and [Pal and Zhang (2017)] for free-floating systems). Fewer studies [Nair and Miller-Hooks (2011); Contardo et al. (2012); Caggiani and Ottomanelli (2013)] for station-based configurations and [Caggiani et al. (2018)] for free-floating systems, focus on the more complex dynamic case, where repositioning activities take place while the system is in operation, so that users pick-up and return bikes, continuously modifying the system state. In all these works, the target inventory level at each station is assumed known, although setting this optimal level is a challenging task, as it should consider the interactions among the inventory levels at different stations [Datner et al. (2017)]. In general, these studies borrow concepts from previous research on one-way car-sharing and formulate mathematical optimization programs based on classical problems of operations research, like routing and inventory optimization. Differences among them lay in the objectives, constraints and solution techniques used. [Alvarez-Valdes et al. (2016)] presents a detailed review of such differences.

All the previous studies address the optimization of repositioning operations. The strategic design of the system (i.e. free-floating vs station-based configuration, or the number and size of stations) and the tactical decisions (i.e. size of the bike fleet and the repositioning level proposed) are considered given and fixed, although they can be sub-optimal. There are relatively few studies in the literature focusing on the strategic design of public bike- 
1 sharing systems. This strategic approach requires an integrated view, considering the trade-off between the user 2 costs and the investment, maintenance and operational costs incurred by the promoting agency [Yuan et al. 3 (2019)]. Because the number of stations, the number of bikes and the number of required rebalancing operations 4 are dependent decision variables, an integrated design framework needs to be proposed. Neglecting part of the system costs, as in [García-Palomares et al. (2012)], where the proposed GIS based solution only considers user costs, or in [Lin and Yang (2011); Lin et al. (2013); Yuan et al. (2019)] where repositioning operations are not considered, oversimplifies the problem. Notice that some authors claim that the redistribution of bicycles over a day can be neglected in the planning phase since this is an operational decision, while only long-term decisions affecting facility investments (bikes, stations, bike lanes), should be considered. The issue here is that the rebalancing level selected has an impact on the strategic design of the system, since there exists a trade-off between the bicycle fleet size and the required repositioning level in order to achieve a particular level of service. More rebalancing saves on bike investment and vice versa.

Other research studies dealing with the strategic design of bike-sharing systems are built on classic facility location problems, where each customer is assigned to one facility with an operational cost that increases with the distance. The design goal is to determine the best locations to build facilities to balance the trade-off between facility investment and operational costs. The typical way to approach location problems is to discretize the space and solve the location design with integer programming techniques. Again, differences appear with respect to the main objective of the optimization, the assumptions considered (included in the mathematical program through the constraints), and the solution techniques used, being the problem generally NP-Hard [Campbell et al. (2002)]. For instance, [Frade and Ribeiro (2015)] propose a linear program to obtain a maximal covering solution given a constrained implementation cost. [Çelebi et al. (2018)] propose an integrated set-covering and queuing model to determine stations' location and their capacity. [Martínez et al. (2012)] formulate a mixedinteger linear program to maximize bike-sharing system revenue, whose solution is obtained through a branch and bound algorithm. [Shu et al. (2013)] use a network flow model, which is solved through linear programming, to determine the optimal number of bicycles, docking positions and rebalancing movements necessary to serve a given demand. In all these cases, the number of stations is assumed given, and the repositioning strategy is periodic every $24 \mathrm{~h}$. More general frameworks try to minimize the overall system cost. For instance, [Yuan et al. (2019)] using a mixed integer linear programming (MILP) model, and [Lin et al (2013)] a hub location inventory model. In both works bike rebalancing between stations is neglected. In addition, [Lin et al (2013)] shows that the computational complexity of the formulation requires the application of a greedy heuristic to find nearoptimal solutions. In fact, the excessive computational burden is a major drawback of integer programming approaches when facing real-world problems (i.e. medium to large scale problems). Nevertheless, from the planning perspective this is not prohibitive since near-optimal solutions, which can be achieved in a reasonable amount of time, suffice. The fact that mathematical programming solutions are "black boxes" allowing neither to gain insights into the system behavior, nor into the existing trade-offs and sensitivity to parameters, is a much more troubling issue.

Continuous approximations (CA) overcome some of these difficulties. The complexity of the problem is simplified, and because the approach is based on analytical modeling of the problem structure, it is able to yield elegant insights. [Daganzo and Newell (1986)] developed a CA approach to solve location problems, and later [Daganzo (2005)] showed that CA yield location designs which are very close to the discrete true optimum. The method has been applied to a number of transportation problems (see [Ansari, et al. (2017)] for a comprehensive review) and in particular to one-way car-sharing systems, as in [Daganzo (2010)], where the near optimal design is obtained assuming a uniform demand level or in [ $\mathrm{Li}$ et al. (2016b)] allowing dynamic and heterogeneous demands, and considering electrical vehicles' charging times. In both studies, only static rebalancing is considered, being in the last case periodic every $24 \mathrm{~h}$. This fixed rebalancing period limits the possibility of increasing the frequency of rebalancing operations to reduce the fleet size. This is the reason why in [Li et al. (2016b)] it is found that the system design is not affected significantly by rebalancing costs. This could be 
1 different if the rebalancing period was defined as a decision variable, allowing intensive repositioning within 2 short periods (i.e. continuous rebalancing) leading to a smaller vehicle fleet. how to economically deploy a public bike-sharing system able to provide reliable service to stochastic trip demands in an urban area. A generalized cost function (enclosing user plus agency costs) is defined in terms of the main decision variables. These are the number and overall size of stations (only in a station-based configuration), the number of bikes, the repositioning period, and the accepted probability of no-service (i.e. system unavailability during peak periods). Minimization of the generalized cost function results in the optimal values for the decision variables that define an optimal system design, without falling into the complexities, details and data greediness of disaggregate models. Different scenarios are modelled, analyzed and compared, including station-based $v s$ free-floating configurations, and the possibility of adopting electric bikes. This modeling approach should be seen as a tool for the strategic design in the planning phase. Afterwards, more detailed models could be used for fine-tuning (e.g. exact location and size of each station, repositioning algorithm and scheduling, or routing of the repositioning trucks). Nonetheless, the direct implementation of the results of the proposed approximate model should not be disregarded, as easiness in the implementation stage has a value in real life [Ansari, et al. (2017)].

\section{Model definition}

\subsection{Model overview and decision variables}

The model is defined over a service region of area $R$, where all demand is generated. The number of bicycle docking stations is introduced into the model by the station density, $\Delta\left[\right.$ stations $\left./ \mathrm{km}^{2}\right]$, being one of the decision variables. So, $\Delta R$ represents the total number of stations, which implicitly divides the service region into subregions, (i.e. the influence area of every single station). In other words, every station is associated with the demand generated in its corresponding sub-region. Assuming fairly uniform distribution of stations in $R$, subregions result of similar size and of fairly convex shape. Stations can be real or virtual. In a station-based model, the station is a real fixed depot that users access in order to take or return the bicycle. In a free-floating model, stations are virtual and bicycles can be freely parked throughout the sub-region.

Demand is composed of requests (demand of bikes at the origin) and returns (demand of parking slots at the destination). Because demand is random and generally asymmetric, the number of requests does not need to coincide with the number returns in a given sub-region and for a period of time. This implies system imbalance and leads to service problems. Users may not find any available bike near their origin, or may not find any available parking spot at their destination (in station-based configurations). These problems could be addressed in the planning phase of the system as follows:

- Bike repositioning. Consider that for every period of duration $h$ [hours] employees with light trucks could move a number of bikes from nearly full to nearly empty sub-regions. The duration $h$ is a decision variable that determines the repositioning intensity in the system.

- Increasing the fleet size. The operating agency could decide to reduce the repositioning intensity (i.e. increase the repositioning period $h$ ) and still offer the same level of service to users (i.e. the same probability of finding an available bicycle and an available parking spot) by providing an additional number of bicycles and parking spots. These should be enough to account for the demand imbalance during the extended repositioning period. To this end, the number of bikes in service, $m$, and the total number of parking slots, $M$, are decision variables.

- Allowing no-service situations. It could be accepted that a fraction, $P_{e}$, of users do not find available bicycles at origin, especially during peak periods. Also, a fraction $P_{f}$ of users may not find available parking slots at destination (only in case of station-based systems). On the one hand, this causes a penalty to users. On the 
other hand, it reduces agency costs. $P_{e}$ and $P_{f}$, are the probabilities of empty and full stations respectively, and are considered as decision variables.

The objective of the model is to optimize these strategic decision variables (i.e. station density $(\Delta)$, fleet size $(m)$, overall number of parking slots $(M)$, repositioning period $(h)$, and no-service probabilities $\left(P_{e}\right.$ and $\left.P_{f}\right)$, in order to minimize the overall system costs, composed of the agency costs (fleet, stations and repositioning) and the user costs (access and no-service penalties).

\subsection{Demand modelling}

\subsubsection{On demand uncertainty, endogeneity and heterogeneity}

Demand generation and trip distribution in bike-sharing systems has been analyzed by a number of research works in the last decade. These works generally exploit the trips' database from some bike-sharing implementation, and try to identify the contextual factors affecting the overall demand generation and trip distribution for bike-sharing systems. This framework allows applying typical demand modelling methodologies to bike-sharing systems. Some examples include [Campbell et al. (2016)] where the selected case studies are the large-scale bike-sharing systems in Beijing, China. This work depicts a multinomial choice model and concludes that mixed land use patterns, favoring short trips, positively impact bike-sharing demand. Results also show that electrical bikes are way more tolerant to longer trip lengths. Also, [Faghih-Imani et al. (2017); Noland et al. (2016)] analyze the socio-economic, land use, terrain elevation and infrastructural factors affecting the demand of bike-sharing systems, using data from the Barcelona, Seville and New York implementations. The analysed data corroborates that demand is higher in places with high population density, with available cycling infrastructure, and near busy subway stations, employment and activity centres, and points of interest. In contrast, demand is lower in higher elevation regions, and in zones with poor coverage and availability of the bike-sharing system. Finally, recent studies point out that bike-sharing demand is negatively influenced by extreme weather conditions [Ashqar, et al. (2019); Kutela and Teng (2019); Scott and Ciuro (2019)].

Despite the previous demand modelling efforts, in the proposed model the average demand for the bikesharing system is considered as an exogenous input. The justification of such simplification follows the reasoning in [Daganzo (2010)]. The system design should target a demand level that is expected to materialize at some point in the future. In addition, results show that optimal designs are robust, so that they are near-optimal for a broad range of demand levels. In this context, and assuming the planning phase of the system, to include complex and uncertain demand models to account for endogeneity (i.e. demand as a function of the system design, while the system design is also a function of the demand level), as is done for instance in [Romero et al. (2012); Martínez el al. (2012)], would over-complicate the model and the interpretation of results.

In addition, the consideration of dynamic and heterogeneous demand profiles (i.e. the inclusion of the detailed evolution of demand in time and space) would turn CA into a very complex optimization problem, as shown in [Li et al. (2016b)]. The obtained insights could then be somehow blurred, because the causality of some results would be more difficult to identify. Furthermore, the model would become data intensive since detailed origin / destination matrixes would be needed. For instance, [Garcia-Palomares et al. (2012); Frade and Ribeiro (2015); Li et al. (2016b)] require O/D demands for small zones (e.g. $500 \mathrm{~m}$ wide) and for every "time step", which needs to be short enough to capture peak demands (i.e. a few hours). This level of detail in the demand characterization is virtually impossible to be robustly predicted during the planning process and for the whole duration of the useful life of the system. In light of this, and because the aim of this research is to obtain a parsimonious model which provides very clear insights, a uniform average demand level is assumed. It must be stressed at this point that this does not mean neglecting demand fluctuations in time and space. The model, as described in the next section, captures random demand variations and the spatial imbalance of requests versus returns. 


\subsubsection{Demand density characterization}

We define $\lambda\left[\right.$ trips $\left./ \mathrm{km}^{2} \cdot \mathrm{h}\right]$ as the average demand density over the service region of area $R$. Then, $\lambda R$ represents the average number of requests in the whole system per unit time. Because of the conservation of the number of bicycles, this needs to be equal to the average number of returns per unit time considering the whole service area, $R$. However, considering a particular location, $r(r \in R)$, the density of requests, $\lambda_{q(r)}$, is generally different than the density of returns, $\lambda_{t(r)}$, leading to system imbalance. The demand imbalance density at location $r$ can be expressed as a fraction of the average demand density, $\lambda$. This is:

$$
\left.\lambda_{t(r)}-\lambda_{q(r)}=\varphi_{(r)} \lambda \quad \text { [imbalance movements } / \mathrm{km}^{2} \cdot \mathrm{h}\right]
$$

where $\varphi_{(r)}$ is a dimensionless variable defining the imbalance level at location $r$. Because of conservation of the number of bikes over the whole service region $R$ :

$$
\int_{R}\left(\lambda_{t(r)}-\lambda_{q(r)}\right) d r=0 \Rightarrow \int_{R} \varphi_{(r)} d r=0
$$

This implies that:

$$
\int_{R_{t}} \varphi_{(r)} d r=-\int_{R_{q}} \varphi_{(r)} d r
$$

where $R_{t}$ is the partition of $R$ where $\lambda_{t(r)}>\lambda_{q(r)}$ (i.e. $\varphi_{(r)}>0$; the density of returns is higher than the density of requests), and $R_{q}$ is the complementary of $R_{t}$ in $R$ (i.e. $\lambda_{q(r)}>\lambda_{t(r)} ; \varphi_{(r)}<0$; more requests than returns). A third partition of $R$ might exist including self-balanced sub-regions, if any.

Then, the average imbalance density (i.e. per unit area and unit time) over the partition $R_{q}$ is expressed as:

$$
\frac{\int_{R_{q}}\left(\lambda_{t(r)}-\lambda_{q(r)}\right) d r}{R_{q}}=\frac{\int_{R_{q}} \varphi_{(r)} \lambda d r}{R_{q}}=\Phi_{q} \lambda
$$

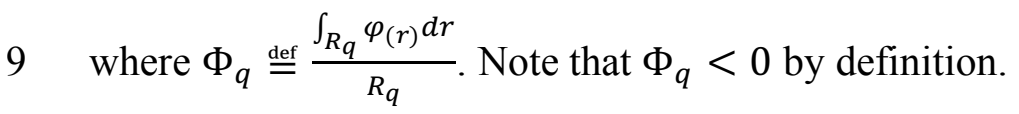

Equivalently, the average imbalance density over $R_{t}$ is:

$$
\frac{\int_{R_{t}}\left(\lambda_{t(r)}-\lambda_{q(r)}\right) d r}{R_{t}}=\frac{\int_{R_{t}} \varphi_{(r)} \lambda d r}{R_{t}}=\Phi_{t} \lambda
$$

where $\Phi_{t} \stackrel{\text { deff }}{=} \frac{\int_{R_{t}} \varphi_{(r)} d r}{R_{t}}, \Phi_{t}>0$ by definition.

Given these definitions and according to the previous conservation equations, $\Phi_{t} R_{t}=-\Phi_{q} R_{q}$ holds, and the average imbalance density over $R$ can be defined as:

$$
\Phi=\frac{\Phi_{t} R_{t}+\left|\Phi_{q}\right| R_{q}}{R}=\frac{2 \Phi_{t} R_{t}}{R}=\frac{2\left|\Phi_{q}\right| R_{q}}{R}
$$

\subsection{Generalized cost function}

Strategic decision variables steer the overall performance of the system from medium to long term. Once selected, their values are difficult to modify because it would imply the redesign of the whole system. In the proposed model, optimal values (i.e. $m^{*}, M^{*}, \Delta^{*}, h^{*}, P_{e}^{*}$ and $P_{f}^{*}$ ) are found by minimizing a generalized cost 
function. This represents the generalized cost of the system (i.e. agency plus users' costs) as a function of the decision variables and parameters that define a particular scenario. Because $m$ and $M$ can be expressed in terms of the other decision variables, and $P_{f}$ will be assumed fixed, as discussed later, the optimization involves 3 degrees of freedom. The optimization is formulated in its Lagrangian form (i.e. unconstrained optimization), where each term of the users' and agency costs in the objective function is weighted by its respective unitary cost, prorated per unit time (i.e. units of $[€ / \mathrm{h}]$ ). The general form of the generalized cost function considered is:

$$
C=C_{I}+C_{O}+C_{R}+C_{A}+C_{N S} \quad[€ / \mathrm{h}]
$$

where $C_{I}$ stands for the infrastructure costs, $C_{O}$ for the operative costs (excluding repositioning), $C_{R}$ for the repositioning costs, $C_{A}$ for the users' access cost, and $C_{N S}$ for the no-service penalty. The following sections are devoted to derive each term of the generalized cost function, $C$. Figure 1 schematically describes the composition of the generalized cost function and its dependency to the decision variables and parameters included in each part.

Generalized Cost Function (GCF)

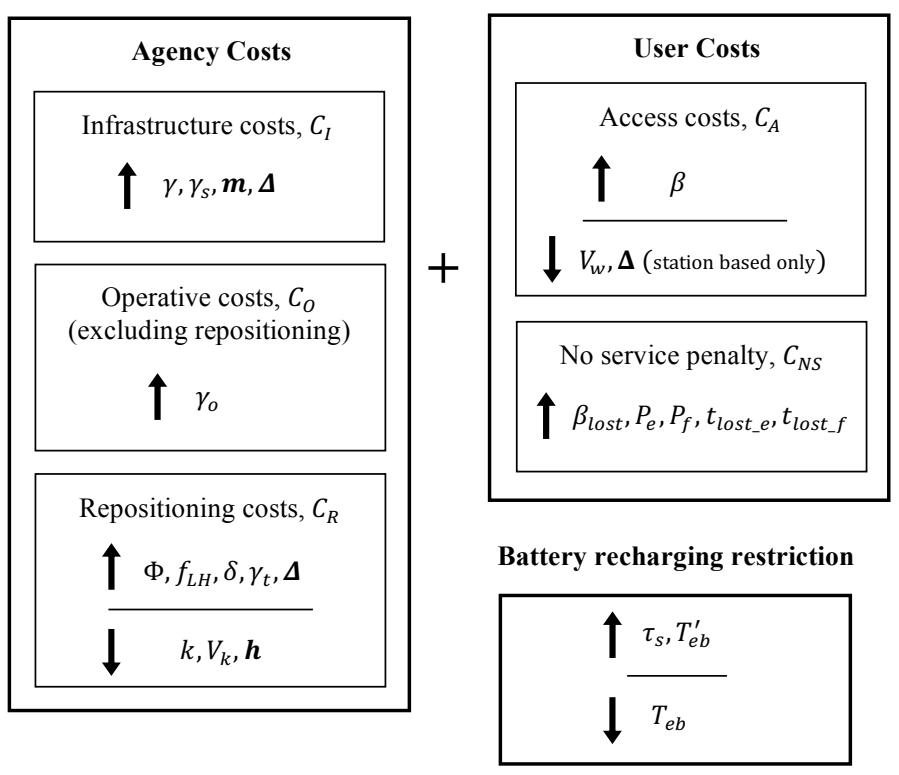

Bicycle fleet, $m$

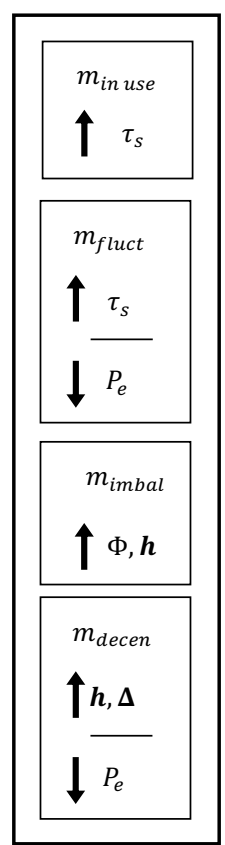

Fig. 1. Schematic description of the composition of the Generalized Cost Function (GCF).

Note: 1) The notation for all the variables and parameters is defined in the following sections and summarized in Tables 1 and 2; 2) Decision variables are in bold

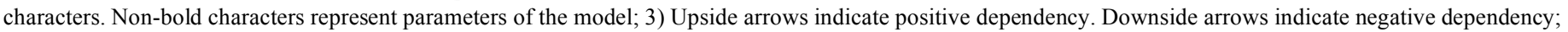
4) In station-based systems, the overall number of bicycle parking slots, $M$, exhibits the same dependencies than the bicycle fleet, $m$.

\subsubsection{Infrastructure costs, $C_{I}$}

Infrastructure costs account for the infrastructure investments made on the system installation. These include bicycles $(m)$ and stations $(\Delta R)$, in station-based systems. Their unitary costs, prorated per unit time, are represented by two cost factors: $\gamma\left[€ / \mathrm{h} \cdot\right.$ bike], the cost of acquiring and renewing bicycles; and $\gamma_{s}[€ / \mathrm{h} \cdot$ station] the construction cost of the stations. In free-floating systems, $\gamma_{s}=0$, because there are no stations. Then:

$$
C_{I}=\gamma m+\gamma_{s} \Delta R \quad[€ / \mathrm{h}]
$$

In Equation 8 and for station-based systems, it is assumed that the cost of stations is independent of the station size (i.e. number of bike parking slots). This considers that the fixed cost per station (e.g. kiosk, power, 
1 communications...) is much higher than the marginal cost of adding additional slots. In spite of this, it is true that included in the infrastructure cost of the system since the allocation of urban space to different transportation modes represents a higher level policy decision in cities. We assume no restrictions in this sense.

\subsubsection{Bicycle fleet size estimation, $m$}

The bicycle fleet size, $m$, can be expressed in terms of the other decision variables, by considering a maximum accepted probability of empty stations, $P_{e}$. In order to accomplish this service level, the fleet size is defined as the sum of the four terms described next.

Average number of bicycles simultaneously being used, $m_{\text {in } u \text { use }}$

This term assures that there are enough available bikes to cover (on average) the demand. By using Little's equation [Little (1961)], this term is obtained as the average demand rate times the average service time (i.e. the average time each bicycle is used per customer). The average demand density is $\lambda$, which translated to the number of trips per unit time in the whole service area results in $\lambda R[$ trips $/ \mathrm{h}]$. The average travel time, $\tau_{s}[\mathrm{~h}]$, is an input parameter. Then:

$$
m_{\text {in use }}=\lambda R \tau_{s}
$$

Safety bicycle stock to account for demand fluctuations, $m_{\text {fluct }}$

Demand is random and subject to fluctuations in time. A safety stock of bicycles is considered in order to cover a possible excess of requests during peak times. This additional stock can be calculated as a probability level multiplied by the standard deviation of the random phenomenon. Assuming the demand rate as a Poisson random variable [Alvarez-Valdes et al. (2016)]; Li et al. (2016b); Lin et al. (2013)], the mean and the variance of the number of requests coincide. So, the standard deviation is expressed as $\sqrt{\lambda R \tau_{s}}$. The probability level is given by the inverse of the standard normal cumulative probability function, $F$, evaluated for the probability $\left(1-P_{e}\right)$, one-sided, $P_{e}$ being the probability of no service at the origin of the trip. Then:

$$
m_{\text {fluct }}=F_{\left(1-P_{e}\right)}^{-1} \sqrt{\lambda R \tau_{s}}
$$

Additional bicycle stock to account for the average imbalance of the system, $m_{\text {imbal }}$

The average imbalance of the system implies that during $h$ (i.e. the rebalancing period) some trips are not balanced, and therefore some stations may experience bicycle scarcity. An additional stock needs to be provided to account for this issue. This value is calculated by integrating the net change in the number of bicycles per unit area and unit time over $R_{q}$ (see Equation 4), realizing that the negative value is only a convention meaning more requests than returns, so that additional bike stock is needed. Obviously, in $R_{t}$ the same amount of additional parking slots will be needed. Equation 4 defines the average net change density (i.e. imbalance movements per unit area and unit time). Considering the region $R_{q}$ and in one repositioning interval, $h$, the additional bike stock required would be:

$$
m_{\text {imbal }}=R_{q} \Phi_{q} \lambda h
$$

Additional bicycle stock to account for the decentralization of the system, $m_{\text {decen }}$

Decentralization accounts for the variation of demand in space. A decentralized system (i.e. $\Delta R$ independent sub-regions) implies that having enough vehicles to serve the overall demands in the whole region $R$ does not imply that enough vehicles are available at the sub-regions where they are needed. So fleet size must be enlarged considering this phenomenon. 
The additional stock to account for the decentralization of the system is proportional to the standard deviation of the net change in the number of vehicles in any sub-region. Assuming independency between requests and returns and considering again a Poisson process (i.e. variance equal to the mean), this additional stock can be computed as:

$$
\operatorname{Var}\left(\lambda_{t(r)}-\lambda_{q(r)}\right)=\operatorname{Var}\left(\lambda_{t(r)}\right)+\operatorname{Var}\left(\lambda_{q(r)}\right)=2 \lambda
$$

This variance is computed in terms of a density (i.e. per unit time and unit area). Then, in one repositioning interval, $h$, and in the influence area of one sub-region, $\frac{1}{\Delta}$, this is $2 \lambda h(1 / \Delta)$. The standard deviation is defined as the root square of the variance, and this value needs to be multiplied by the number of sub-regions (i.e. $\Delta \mathrm{R}$ ). Again, the safety stock considered is weighted by a probability level $F_{\left(1-P_{e}\right)}^{-1}$, being $F^{-1}$ the inverse of the onesided standard normal cumulative probability density function. Then we finally obtain:

$$
m_{\text {decen }}=F_{\left(1-P_{e}\right)}^{-1} R \sqrt{2 \lambda h \Delta}
$$

\section{Summary}

The total required bicycle fleet size is the sum of the average number of bikes to serve the peak demand, plus safety stocks to account for random demand fluctuations, average imbalance and decentralization of the system. This is:

$$
\begin{aligned}
& m=m_{\text {in use }}+m_{\text {fluct }}+m_{\text {imbal }}+m_{\text {decen }} \\
& m=\lambda R \tau_{s}+F_{\left(1-P_{e}\right)}^{-1} \sqrt{\lambda R \tau_{s}}+R_{q} \Phi_{q} \lambda h+F_{\left(1-P_{e}\right)}^{-1} R \sqrt{2 \lambda h \Delta}
\end{aligned}
$$

\subsubsection{Estimation of the overall size of stations, $M$}

In station-based systems, the overall number of available parking slots at stations, $M$, needs to be defined in the planning phase. $M$ must be equal to the fleet size, $m$, plus the additional slots to account for all the fluctuations. This includes the demand fluctuations in subzones with more returns than requests, the average imbalance in $R_{t}$, and the additional slots to account for decentralization of the system, where more returns than requests happen. The derivation of these four terms is equivalent to the estimation of the fleet size, but considering the probability of not finding an available parking slot at destination, $P_{f}$.

$$
M=m+F_{\left(1-P_{f}\right)}^{-1} \sqrt{\lambda R \tau_{s}}+R_{t} \Phi_{t} \lambda h+F_{\left(1-P_{f}\right)}^{-1} R \sqrt{2 \lambda h \Delta}
$$

Note that the third term in Equation 16 is equivalent to $R_{q}\left|\Phi_{q}\right| \lambda h$ (see Equation 6).

\subsubsection{Operative costs (excluding repositioning), $C_{O}$}

Operative costs include bicycle maintenance and repair, control and system administration. It is considered that these costs are related to bicycle usage and are assumed to be proportional to the demand. $\lambda R$ is the average number of trips served per unit time, and $\gamma_{o}$ is defined as the unitary operative cost per trip, considering the prorated cost of all the concepts involved. Then, the operative costs are formulated as:

$$
C_{O}=\gamma_{o} \lambda R \quad[€ / \mathrm{h}]
$$

This approach neglects the possibility of economies of scale with respect to operative costs. This means that the extrapolation of $\gamma_{o}$ values to very different demand levels in relation to from where they were estimated must be done with caution. 


\section{1}

\subsubsection{Repositioning costs, $C_{R}$}

In order to balance the system to its original configuration, for every period $h$ the imbalanced bicycles are moved to a more convenient location. This set of tasks is performed by agency employees and implies an additional operative cost. Due to its modeling complexity this part of the operative cost is analyzed here separately.

The average number of repositioning operations (i.e. bikes to be moved) is equal to the average system imbalance plus the average system decentralization (see Section 3.3.1.1 devoted to fleet size estimation for a description of these concepts). This is generally an overestimation because some compensation between both phenomena could exist. Because all sub-regions experience, to some degree, imbalance and decentralization, the assumptions of this rebalancing model imply that all sub-regions are visited by repositioning trucks every period $h$. In practice, stations with few bikes to be rebalanced would not be visited until the amount of repositioning operations to be performed was significant. In contrast, other stations may be visited several times during $h$. In this context, the rebalancing period $h$, must be understood as the inverse of the average number of visits per station and unit time. In addition, repositioning operations are considered to be continuously performed during $h$. So, the interpretation of $h$ should not be that every $h$ units of time all the sub-regions are found with their optimal number of bicycles. This is not the case. What happens is that during a period $h$ all the imbalance movements have been performed. It should be understood that when a sub-region is left with its optimal number of bicycles, it may start being imbalanced immediately thereafter.

Repositioning is assumed to be performed with trucks (or vans with a trailer) with a capacity of $k$ bikes, and with one driver. Trucks visit stations (or sub-regions) and load or unload bikes, depending on if there is an excess (i.e. in $R_{t}$, where $\varphi_{r}>0$ ) or a shortage of bikes (i.e. in $R_{q}$, where $\varphi_{r}<0$ ). Sub-regions are left with their optimal number of bikes. If trucks fill up, they need to travel to sub-regions with a shortage of bikes. If trucks become empty, they need to travel the opposite way. With such assumptions, repositioning trucks perform two types of "trips" between sub-regions. There are peddling trips, where trucks are visiting contiguous stations (i.e. either loading or unloading bikes, with partly full trucks), and line-haul trips where trucks travel full from sub-regions in $R_{t}$ to sub-regions in $R_{q}$ or return empty in the opposite direction.

\subsubsection{Line-haul distance}

Because of the truck capacity restriction, $k$, and because of the demand patterns leading to the systematic bicycle imbalance of different zones, generally far apart, full and empty line-haul trips appear. The average distance of these line-haul trips, $E_{[L H]}$, depends on the particular distribution of the imbalance levels over the service region $R$ (i.e. the spatial distribution of $\varphi_{(r)}$ ), and can be approximated by the distance between the centers of gravity of the partitions $R_{q}$ and $R_{t}$ with respect to $\varphi_{(r)}$. Furthermore, $E_{[L H]}$ can be expressed as a fraction of the diameter of $R$, as proposed in [Larson and Odoni (1981)]. In this context, the expected line-haul travel distance, $E_{[L H]}$, can be generalized as:

$$
E_{[L H]}=f_{L H} \sqrt{R} \quad[\mathrm{~km} / \text { line-haul trip }]
$$

where $\sqrt{\mathrm{R}}$ approximates the "diameter" of the service region, assuming a fairly compact and convex region, and $f_{L H}$ is the parameter between 0 and 1 which needs to be derived from the spatial distribution of $\varphi_{(r)}$.

The number of line-haul trips between sub-regions in $R_{t}$ to sub-regions in $R_{q}$ (i.e. full trips) can be obtained as the average imbalance in the system during a period $h$, over the capacity of the repositioning trucks. This number needs to be doubled, because there are an equivalent number of return (empty) trips. Note that the decentralization of the system, which leads to random imbalance levels for some stations and periods of time, does not contribute to the number of line-haul trips, as this phenomenon is addressed by peddling trips between stations. Considering that the average imbalance of the system can be expressed as $R_{q} \Phi_{q} \lambda h$, the number of linehaul trips is: 


$$
\text { \# line - haul trips }=\frac{2 R_{q} \Phi_{q} \lambda h}{k}
$$

Therefore, the total line-haul distance is obtained as:

$$
D_{[L H]}=\frac{2 R_{q} \Phi_{q} \lambda h f_{L H} \sqrt{R}}{k} \quad[\mathrm{~km}]
$$

\subsubsection{Peddling distance}

The total peddling distance can be computed as the solution to the transportation problem, where the objective is to minimize the cost of distributing a product (i.e. the bicycles) from a number of sources (or origins) to a number of destinations. [Daganzo and Smilowitz (2004)] developed simple approximations to the solution, useful to predict the performance of complex logistic systems in the planning stages. According to this reference, the average peddling distance per visited station, $E_{[P D]}$, is proportional to the inverse of the root-square of the density of the points to visit [visits $\left./ \mathrm{km}^{2}\right]$.

\section{Peddling distance in station-based systems}

In station-based systems, bikes are found only at stations, so that the density of the points to visit by the rebalancing trucks is precisely the density of stations, $\Delta$. Therefore:

$$
E_{\left[P D_{-} \text {station }\right]}=\frac{1.1}{\sqrt{\Delta}} \quad[\mathrm{km} / \text { visited station }]
$$

where 1.1 is the proportionality constant derived in [Daganzo and Smilowitz (2004)]. Note that $\frac{1}{\sqrt{\Delta}}$ could be interpreted as an approximation to the "diameter" of the sub-region, assuming fairly compact and convex subregions. Considering that the total number of stations to visit is $\Delta R$, the total peddling distance in station-based systems can be expressed as:

$$
D_{\left[P D_{-} \text {station }\right]}=1.1 R \sqrt{\Delta} \quad[\mathrm{km}]
$$

\section{Peddling distance in free-floating systems}

In free-floating systems, bicycles can be found at any location within the service region. This means that repositioning trucks need to pick-up bikes one by one in sub-regions with bikes in excess. In contrast, it is assumed that bikes are delivered all together in a central location of sub-regions with a bicycle deficit. The total peddling distance is approximated, as previously, using the formulae derived in [Daganzo and Smilowitz (2004)]. However, with the free-floating assumptions, the density of points to visit is different when picking-up with respect to when delivering bikes.

In sub-regions in $R_{t}$ (i.e. bikes in excess), the number of idle bicycles, $m_{i(h)}$, candidates for being picked-up just at the end of the repositioning period, can be expressed as:

$$
m_{i(h)}=\left(m-\lambda R \tau_{s}\right) \frac{R_{t}}{R}+R \sqrt{2 \lambda h \Delta}+R_{q} \Phi_{q} \lambda h
$$

The first term in Equation 23 stands for the equilibrium number of idle vehicles. Note that only sub-regions in $R_{t}$ are considered. The second term accounts for the expected number of vehicles in excess due to decentralization effects (see Equation 13 with a probability level equal to one standard deviation from the mean). The third and last term of Equation 23 stands for the average imbalance of the system, which is positive in $R_{t}$. Then the expected peddling distance per picked-up bicycle, $E_{\left[P D_{-} \text {floating_pickup }\right]}$, is: 


$$
E_{\left[P D_{-} \text {floating_pickup }\right]}=1.1 \sqrt{\frac{R_{t}}{m_{i(h)}}} \quad[\mathrm{km} / \text { pick-up }]
$$

The total picking-up peddling distance, $D_{\left[P D_{\text {ffloating_pickup }}\right]}$ is obtained by multiplying the expected distance in Equation 24, times the average number of bikes to be rebalanced. This is:

$$
D_{\left[P D_{-} \text {floating_pickup }\right]}=\left(1.1 \sqrt{\frac{R_{t}}{m_{i(h)}}}\right) \cdot\left(R \sqrt{2 \lambda h \Delta}+R_{q} \Phi_{q} \lambda h\right) \quad[\mathrm{km}]
$$

Bike delivery is done just at a single location for each sub-region, so that the total peddling distance in delivering rebalanced bikes is equivalent to the station-based case, just considering that the number of subregions in $R_{q}$ where the bicycles are to be delivered is $\Delta R_{q}$. Then:

$$
D_{\left[P D_{-} \text {floating_deliver }\right]}=1.1 R_{q} \sqrt{\Delta} \quad[\mathrm{km}]
$$

The total peddling distance when rebalancing free-floating bike-sharing systems, $\mathrm{D}_{\left[P D_{-} \text {floating] }\right.}$, is simply obtained as the sum of the expected distances in picking-up and delivering bikes (i.e. Equations 25 and 26).

\subsubsection{Repositioning teams}

The time required to rebalance the system is invested in traveling between different sub-regions and in loading/unloading bicycles to/from the trucks. This total repositioning time can be expressed per unit time, and this would correspond to the number of required repositioning teams. This is formulated as:

$$
\text { \# repo teams }=\left[\frac{D_{[L H]}+D_{[P D]}}{V_{k}}+\left(R \sqrt{2 \lambda h \Delta}+R_{q} \Phi_{q} \lambda h\right) 2 \delta\right] \frac{1}{h}
$$

Where $V_{k}$ is the average travelling speed of repositioning trucks in the service region, so that the first term in Equation 27 reflects the total travelling time. The second term in brackets is the average number of bikes to be rebalanced, and $\delta$ is the average time required to load or unload one bike to/from the truck. The factor 2 affecting $\delta$ accounts for the fact that all bikes need to be loaded and unloaded. Take into account that in free-floating systems $\delta$ will be higher, since the economies of scale of picking-up bikes at a single location (i.e. the station) are lost. Finally, both terms are divided by $h$, the repositioning period, to express the total repositioning time per unit time. It is interesting to note that the terms of Equation 27 accounting for the average imbalance of the system are independent of $h$, while those accounting for the decentralization decrease with $h$.

\subsubsection{Repositioning costs}

Repositioning costs account for the depreciation, maintenance and operation of repositioning trucks, including the labor, which is the main cost. $\gamma_{t}[€ / \mathrm{h}]$ is the prorated cost per unit time of one repositioning team, so that repositioning costs are obtained as:

$$
C_{R}=\gamma_{t} \cdot \# \text { repo teams } \quad[€ / \mathrm{h}]
$$

\subsubsection{User access cost, $C_{A}$}

The accessibility of the system is determined by the users' average access time to bicycles. It is assumed that users access the bicycle location by walking. Then, the access cost can be calculated by considering the average access distance $[\mathrm{km}]$, the walking speed $V_{w}[\mathrm{~km} / \mathrm{h}]$, and the value of time $\beta[€ / \mathrm{h}]$, which monetizes the access time. The cost per customer needs to be multiplied by the average demand rate $\lambda R$ to account for all users in the system. 


$$
C_{A}=(E[\text { access origin }]+E[\text { access destination }]) \cdot \frac{\beta \lambda R}{V_{w}} \quad[€ / \mathrm{h}]
$$

The expected access distance, at the origin but also at the destination (i.e. from where the bike is left to the desired final destination), depends on whether the system is configured as station-based or free-floating. On the one hand, in station-based systems the user walks to the nearest station with available bikes. So, the access distance depends on the station density. The same happens at the destination. On the other hand, in the freefloating case the user walks to the nearest available bicycle. So, the access distance at the origin depends on the available bicycle density (i.e. the idle fleet, $m_{i}$, per unit area). Also, it is assumed that the user leaves the bike just at the door of his destination, so that the access costs at destination are null in the free-floating scenario.

Considering a L1 metric and assuming fairly convex sub-regions, the average access distance can be approximated by half (i.e. $1 / 4$ in each of the 2 dimensions) the average diameter of the influence region of one station, or of one idle bicycle, for free floating configurations and assuming uniformly distributed idle bicycles in the sub-region [Larson and Odoni (1981)]. This is:

$$
\text { Station-based: } \quad E[\text { access origin }]=E[\text { access destination }]=\frac{1}{2 \sqrt{\Delta}} \quad[\mathrm{km}]
$$

$$
\text { Free-floating: } \quad E[\text { access origin }]=\frac{1}{2} \cdot \sqrt{\frac{R}{m_{i}}}
$$

Where the average idle fleet, $m_{i}$, is estimated as the total fleet minus the average number of bicycles in use:

$$
m_{i}=m-\lambda R \tau_{s}
$$

Note that the idle bicycle fleet is variable during the repositioning period, $h$, because of the imbalance and decentralization phenomena. Therefore, the average accessibility level of free-floating systems is not constant in time and space.

Under the previous assumptions, the access distance in free-floating systems does not depend on the density of sub-regions, $\Delta$, but only on the number of available bicycles. This means that while the reduction of $\Delta$ implies a reduction of agency costs, there is no associated user cost. In the absence of trade-off, $\Delta$ is minimized for a situation where the whole service region forms a single sub-region. This result is not realistic since in such a case, the assumption of uniform distribution of available vehicles in the sub-region would not hold, and rebalancing operations would be greatly underestimated. For this reason, it is necessary to set a minimum number of sub-regions in the free-floating scenario, which translates to a minimum $\Delta$ as a restriction in the optimization. This restriction will be binding. $\Delta_{\min }=1.5$ [sub-regions $\left./ \mathrm{km}^{2}\right]$ is selected considering that the uniformity distribution is acceptable in sub-zones of $\frac{1}{\Delta_{\min }}=0.67\left[\mathrm{~km}^{2}\right]$ leading to a worst case average access distance of approximately $400 \mathrm{~m}$ (the maximum access distance would be the double of this) when the bicycle availability is minimum (i.e. one single bike in the sub-region). This is the standard for the worst accessibility level of most bike-sharing systems [Lin \& Yang (2011); Garcia-Palomares et al. (2012)] and also the usual standard accepted for public transportation systems [TRB (2013)]. Consider that [Millward et al. (2017)] found that the often-used walking range is shorter than $600 \mathrm{~m}$, and very few exceed $1,200 \mathrm{~m}$.

\subsubsection{No-service penalty, $C_{N S}$}

This term of the generalized cost function aims to take into account the extra costs users perceive when they do not find any available bicycle, or any free parking slot (in station-based systems). When a user faces this noservice situation, he might decide to wait, to go to another sub-region, or to use another transportation mode. In any case, this implies a penalty to the user. These user costs are modeled considering the decision variables $P_{e}$ 
1 and $P_{f}$, the probability of empty or full stations, respectively, affecting the total demand of the system, $\lambda R$. Then, 2 the overall no-service penalty in the system can be formulated as:

$$
C_{N S}=\lambda R \beta_{\text {lost }}\left(P_{e} t_{\text {lost_e }}+P_{f} t_{\text {lost_f }}\right)
$$

where $\beta_{\text {lost }}$ is the users' perceived value of lost time (i.e. in general $\beta_{\text {lost }}>\beta$ ) and $t_{\text {lost } e}, t_{\text {lost_f } f}$ are the costs of no-service (in units of time), either due to an empty or full station. By definition, $P_{f}$ is null in free-floating systems, because there are no stations. In station-based systems, $P_{f}$ depends on the total number of bicycle parking slots, $M$. Because $P_{f}$ decreases with $M$, and there is no agency cost associated with $M$ (recall that it has been assumed a fixed cost per station, independent of their size), the optimization procedure would lead $P_{f} \rightarrow 0$ and $M \rightarrow \infty$. To avoid this situation, $P_{f}$ is considered fixed at $1 \%$. This is consistent with the previous assumption of no (or very little) restriction in terms of urban space consumption, and from the user perspective it eliminates the more penalizing situation of not knowing what to do with the bicycle once at the destination.

\subsection{Extension to electrical bikes}

Station-based sharing systems are especially suited for the use of electrical bikes. Battery recharging is the only additional requirement, and this task can be easily performed while e-bikes are docked at stations. The previous model for station-based bike-sharing systems can be easily extended to the e-bikes context by considering that e-bikes and e-stations might be more expensive and by including the battery recharging restriction. This can be done by imposing, over the whole system, that the average battery consumption per unit time has to be lower than the average battery recharging per unit time. Otherwise, the overall battery level in the system would be reduced with time, and eventually would fail in serving the demand. Note that this does not mean that during a particular peak period the overall battery level could not be reduced, but that on average this deficit will be recovered. This assumes $24 / 7$ operating period, the worst case situation, because batteries cannot use closed periods to recharge.

On the one hand, $T_{e b}$ is defined as the available usage time of a fully charged e-bike. This can be estimated as $D_{e b} / V_{e b}$, the ratio of the maximum distance covered with a fully charged e-bike over the average cycling speed in an urban environment. On the other hand, $T_{e b}^{\prime}$ is defined as the time required to fully charge the e-bikes' battery from empty. Therefore $T_{e b} / T_{e b}^{\prime}$ is the time available for using the e-bike per unit time charging. With these definitions the previous battery recharging restriction can be expressed as:

$$
\lambda R \tau_{s}<m_{i} \frac{T_{e b}}{T_{e b}^{\prime}}
$$

Recall from Equation 32 that $m_{i}$ is the average number of idle bicycles (i.e. recharging at stations). Substituting Equation 32 into Equation 34, the battery recharging restriction is simplified to:

$$
m>\lambda R \tau_{s}\left(1+\frac{T_{e b}^{\prime}}{T_{e b}}\right)
$$

If the fleet size (see Equation 15) does not fulfill this restriction, then additional e-bikes would be needed just to provide enough battery level. Otherwise, the battery restriction is not binding, meaning that turning the system into electric does not imply additional fleet. Note that this last situation will happen if the additional fleet required to account for the temporal demand fluctuations and the various sources of stations' imbalance represents a 
1 fraction larger than $\frac{T_{e b}^{\prime}}{T_{e b}}$ of the number of bicycles in use (i.e. $\lambda R \tau_{s}$ ). Or in other words, that the most restrictive

2 case in terms of battery recharging would be a system with very low imbalance and with uniform demands.

\subsection{On the mathematical properties of the generalized cost function}

4

The generalized cost function (GCF) derived in the previous sections acts as an objective function, and will be minimized with respect to the decision variables in order to obtain the optimal system design. The continuous approximations modeling framework allows ensuring that the proposed GCF is well behaved. The GCF is continuous and differentiable, being the sum of continuous and differentiable functions. Moreover, the optimization problem for each decision variable could be expressed as:

$$
G C F^{*}=\min \left\{G C F=A x^{a}+B x^{-b}: 0<x \leq \infty ; a, b>0\right\}
$$

Where $x$ is the decision variable, and the optimum is achieved for some $x^{*}$. Problems of this form are known as generalized EOQ optimizations, a terminology inherited from the logistics discipline where the economic order quantity (EOQ) is the order quantity that minimizes the total holding and ordering costs. The properties of this type of optimization have been thoroughly studied (e.g. [Daganzo, 2005]), proving the existence of a single and robust minimum. The robustness property, which means that the curvature of the GCF near the optimum is low, implies that the sensitivity of the optimal values of the decision variables to variations in the input parameters is equally low. This is a nice property for an optimization problem in the planning stage of a system, because it ensures reliable solutions although many inputs being highly uncertain. It can be proved that the GCF is more robust for lower values of the powers $a$ and $b$.

\section{The Barcelona's Bicing case study: parameter estimation, model validation and system optimization}

Since 2007, Bicing, the bike-sharing system in the city of Barcelona (Spain), has been operative. Bicing is a station-based system where members are identified using a membership card. Today it covers all the city districts, and its 106,430 members perform approximately 1.5 million trips every month [www.bicing.cat].

\subsection{Parameter estimation for the Bicing system}

Table 1 presents the main design variables of the Bicing system, and Table 2 summarizes the parameter estimation in the context of Barcelona's Bicing bike-sharing system. The unitary costs estimated in Table 2 are slightly higher than those reported in [Frade and Ribeiro (2015)] for the city of Coimbra in Portugal. 
1 Table 1. Barcelona Bicing's system design variables

\begin{tabular}{|c|c|c|c|c|}
\hline Variable description & Notation & Units & Value & Source \\
\hline Available fleet size & $m$ & [bikes] & 5236 & Data from the Barcelona's Bicing web service ${ }^{1}$ \\
\hline Average bike daily usage & - & [trips/bike·day] & 9.52 & Total daily demand / available fleet size \\
\hline Total number of parking slots & $M$ & [slots] & 10246 & Data from the Barcelona's Bicing web service \\
\hline Slots / fleet ratio & $M / m$ & [slots/bike] & 1.96 & \\
\hline Stations density & $\Delta$ & [stations $\left./ \mathrm{km}^{2}\right]$ & 8.20 & 402 stations in $49 \mathrm{~km}^{2}$ \\
\hline Repositioning period & $h$ & [hours] & 8.39 & $\begin{array}{l}\text { On average the repositioning frequency of stations is } 2.86 \text { times/day. This } \\
\text { includes } 10 \% \text { of the stations that are visited more than } 6 \text { times/day and } \\
20 \% \text { that are not visited. } h \text { is obtained as the inverse of the average } \\
\text { repositioning frequency. Data from the Barcelona's Bicing web service. }\end{array}$ \\
\hline Repositioning operations & - & [bikes/day] & 13164 & $\begin{array}{l}\text { Data from the Barcelona's Bicing web service. Confirmed by [Alonso et } \\
\text { al. (2015)]. }\end{array}$ \\
\hline Number of repositioning teams & \#repo teams & - & 24 & $\begin{array}{l}\text { Barcelona's Bicing hires } 115 \text { workers to perform repositioning operations } \\
\text { [López (2009)]. The estimation of the \#repo teams assumes } 24 / 7 \text { system } \\
\text { operation and an annual working shift of } 1826 \mathrm{~h} \text {. }\end{array}$ \\
\hline Probability of empty stations & $P_{e}$ & - & 0.1355 & $\begin{array}{l}\text { Estimated from data provided by the Barcelona's Bicing web service, } \\
\text { from where the fraction of the operating time when a particular station is }\end{array}$ \\
\hline Probability of full stations & $P_{f}$ & - & 0.1247 & $\begin{array}{l}\text { full or empty can be obtained. The average probability is simply } \\
\text { computed as a weighted average of these fractions, where the weights are } \\
\text { the average daily demand of each station. }\end{array}$ \\
\hline
\end{tabular}

4 Table 2. Input parameters for the Barcelona case study.

\begin{tabular}{|c|c|c|c|c|c|}
\hline & Parameter description & Notation & Units & Value & Source \\
\hline \multirow{9}{*}{ 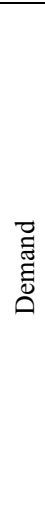 } & Area of the service region & $R$ & {$\left[\mathrm{~km}^{2}\right]$} & 49 & Barcelona's Bicing website (www.bicing.cat) \\
\hline & Average demand density & $\lambda$ & {$\left[\operatorname{trips} / \mathrm{h} \cdot \mathrm{km}^{2}\right]$} & 42.37 & $\begin{array}{l}\text { Data from the Barcelona's Bicing web service. This corresponds to } \\
\text { an annual demand of } 18.2 \text { million trips. }\end{array}$ \\
\hline & \multirow{3}{*}{$\begin{array}{l}\text { Average imbalanced demand } \\
\text { fractions }\end{array}$} & $\Phi_{t}$ & - & 0.129 & \multirow{3}{*}{$\begin{array}{l}\text { Estimated from data provided by the Barcelona's Bicing web service } \\
\text { (see Section 4.1). } \Phi=\frac{\Phi_{t} R_{t}+\left|\Phi_{q}\right| R_{q}}{R} \text { (See Equation 6). }\end{array}$} \\
\hline & & $\Phi_{q}$ & - & -0.108 & \\
\hline & & $\Phi$ & - & 0.118 & \\
\hline & \multirow{2}{*}{ Imbalance partitions of $R$} & $R_{t}$ & {$\left[\mathrm{~km}^{2}\right]$} & $0.458 \cdot R$ & \multirow{2}{*}{$\begin{array}{l}\text { Estimated from data provided by the Barcelona's Bicing web service } \\
\text { (see Section 4.1) }\end{array}$} \\
\hline & & $R_{q}$ & {$\left[\mathrm{~km}^{2}\right]$} & $0.549 \cdot R$ & \\
\hline & \multirow[b]{2}{*}{ Average service time } & \multirow[b]{2}{*}{$\tau_{s}$} & \multirow[b]{2}{*}[\mathrm{min}]{} & $13.28(\mathrm{~s})^{2}$ & \multirow{2}{*}{$\begin{array}{l}\text { Barcelona's Bicing website (www.bicing.cat). In free-floating } \\
\text { systems, a max. reservation time of } 15 \mathrm{~min} \text { is considered. In this } \\
\text { context, bicycles are on hold } 7.5 \mathrm{~min} \text { on average. This is added to the } \\
\text { average service time. }\end{array}$} \\
\hline & & & & $20.78(f)$ & \\
\hline \multirow{5}{*}{ 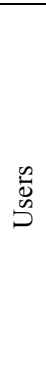 } & Average walking speed & $V_{w}$ & {$[\mathrm{~km} / \mathrm{h}]$} & 3.6 & Catalonia's mobility observatory $^{3}$ \\
\hline & Users' average value of time & $\beta$ & {$[€ / \mathrm{h}]$} & 11.4 & $\begin{array}{l}\text { Official value used for transport investment appraisal in Barcelona } \\
{[\text { ATM - Autoritat del Transport Metropolità }]^{4}}\end{array}$ \\
\hline & Users' average value of time lost & $\beta_{\text {lost }}$ & {$[€ / \mathrm{h}]$} & 26.7 & $\begin{array}{l}\beta_{\text {lost }}=2.34 \beta[\text { Asensio and Matas }(2008)] \text { for an average trip }(94 \% \\
\text { commuters with scheduled arrival time) in the Barcelona region. }\end{array}$ \\
\hline & No-service penalty (empty) & $t_{\text {lost_e }_{-}}$ & {$[\mathrm{min}]$} & 10.2 & $\begin{array}{l}\text { Average users' wait at an empty station [Ajuntament de Barcelona } \\
(2007)]\end{array}$ \\
\hline & No-service penalty (full) & $t_{\text {lost_f }}$ & {$[\mathrm{min}]$} & 20.4 & $\begin{array}{l}\text { Post-process waits feel longer than pre-process delays. A factor of } 2 \\
\text { is considered [Maister (1984)] }\end{array}$ \\
\hline
\end{tabular}

\footnotetext{
${ }^{1}$ Barcelona's Bicing web service provides data regarding the location (x, y, z coordinates) and size of stations, and their real time bike occupancy (with per minute updates). http://opendata-ajuntament.barcelona.cat/data/ca/dataset/bicing. Data was extracted on May $7^{\text {th, }} 2014$.

${ }^{2}$ (s) stands for station-based systems; (f) stands for free-floating systems.

${ }^{3}$ Mobilitat. Generalitat de Catalunya. http://mobilitat.gencat.cat/es/serveis/mitjans_de_transport/a_peu/

${ }^{4}$ This is approximately $80 \%$ of the average hourly income in Spain.
} 


\begin{tabular}{|c|c|c|c|c|c|}
\hline \multirow{5}{*}{ 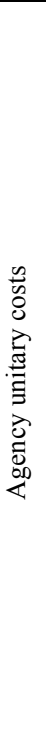 } & $\begin{array}{l}\text { Bicycle unitary cost and } \\
\text { depreciation }\end{array}$ & $\gamma$ & {$[€ / \mathrm{h} \cdot$ bike $]$} & $0.0279(\mathrm{~s})$ & $\begin{array}{l}\text { Bicing bicycles cost } 400 € \text { each and they have a useful life of } 1.7 \\
\text { years [López (2009)]. This short lifespan of bicycles is in accordance } \\
\text { with the arguments and data provided in [Martinez et al. (2012)], } \\
\text { where it is asserted that in systems under operation, bicycle theft and } \\
\text { vandalism has proven to be high. In addition, } \gamma \text { includes the fact that } \\
4 \% \text { of the bikes are not available due to maintenance } \\
\text { (www.bicing.cat). }\end{array}$ \\
\hline & & & & 0.0549 (f) & $\begin{array}{l}\text { In free-floating systems, bikes incorporate all the functionalities of } \\
\text { stations. Free-floating bikes cost } 786 € \text { each [Lee (2017)]. Same } \\
\text { previous assumptions are considered. }\end{array}$ \\
\hline & $\begin{array}{l}\text { Station unitary cost and } \\
\text { depreciation }\end{array}$ & $\gamma_{s}$ & {$[€ / \mathrm{h} \cdot$ station $]$} & 0.311 & $\begin{array}{l}11 \text { M€ for } 402 \text { stations in the Bicing system, considering a useful life } \\
\text { of } 10 \text { years [López (2009)]. }\end{array}$ \\
\hline & Operative cost per trip & $\gamma_{o}$ & {$[€ /$ trip $]$} & 0.6369 & $\begin{array}{l}\text { Operative cost of the Bicing system (excluding repositioning) in } \\
2010 \text { was } 7.1 \mathrm{M} € \text {. Demand during the same period was } 11.1 \text { million } \\
\text { trips [López (2009)]. }\end{array}$ \\
\hline & $\begin{array}{l}\text { Cost of a repositioning team (truck } \\
+ \text { labor) }\end{array}$ & $\gamma_{t}$ & {$[€ / \mathrm{h} \cdot$ team $]$} & 22.8 & $\begin{array}{l}\text { The total repositioning cost (trucks }+ \text { labor) of the Bicing system } \\
\text { during } 2010 \text { was of } 3.2 \mathrm{M} € \text {, for a total of } 115 \text { workers [López } \\
(2009)] . \gamma_{t} \text { is obtained considering an annual working shift of } 1826 \mathrm{~h} \\
\text { and an efficiency factor of } 2 / 3 \text { (i.e. } 1 / 3 \text { of the available hours are lost } \\
\text { times and inefficiencies). }\end{array}$ \\
\hline \multirow{5}{*}{ 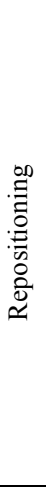 } & Capacity of a repositioning truck & $k$ & [bikes] & 32 & Truck capacity in Barcelona's Bicing system. \\
\hline & $\begin{array}{l}\text { Average cruising speed of } \\
\text { repositioning trucks }\end{array}$ & $V_{k}$ & {$[\mathrm{~km} / \mathrm{h}]$} & 20.6 & $\begin{array}{l}\text { Average cruising speed for motorized vehicles in the city of } \\
\text { Barcelona [Ajuntament de Barcelona (2016)] }\end{array}$ \\
\hline & $\begin{array}{l}\text { Line-Haul distance repositioning } \\
\text { parameter }\end{array}$ & $f_{L H}$ & - & 0.339 & $\begin{array}{l}f_{L H} \sqrt{R} \text { is the } \mathrm{L} 1 \text { distance between the centers of gravity of partitions } \\
R_{t} \text { and } R_{q} \text { in } R \text {, where each station location is weighted by its } \\
\text { respective unbalance level } \varphi_{(r)} \text {. Data from the Barcelona's Bicing } \\
\text { web service. }\end{array}$ \\
\hline & & & & $37.5(\mathrm{~s})$ & $\begin{array}{l}\text { In Barcelona's Bicing system it takes } 20 \mathrm{~min} \text { to load / unload one } \\
\text { truck (i.e. } 32 \text { bikes) })^{5} \text {. }\end{array}$ \\
\hline & Time to load / unload one bike & $\delta$ & [seconds] & $63.75(f)$ & $\begin{array}{l}\text { Pick-up in free-floating systems } \delta_{p}=90 \mathrm{~s} \text { [Pal and Zhang (2017)] } \\
\text { (dispersed bicycles). Delivery operation is equivalent to station- } \\
\text { based systems } \delta_{d}=37.5 \mathrm{~s} . \delta \text { represents the average value. }\end{array}$ \\
\hline \multirow{5}{*}{ 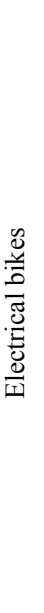 } & Electrical Bicycle depreciation & $\gamma_{e b}$ & {$[€ / \mathrm{h} \cdot$ bike $]$} & 0.0838 & $\begin{array}{l}\text { Electrical Bicing pilot in Barcelona. Electrical bikes cost 1,200€ each } \\
\text { [Ajuntament de Barcelona (2014); La Vanguardia (2014)]. Useful } \\
\text { life and maintenance rate are assumed to be the same as conventional } \\
\text { bikes (i.e. } 1.7 \text { years and 4\%). }\end{array}$ \\
\hline & Electrical Station depreciation & $\gamma_{S_{-} e b}$ & {$[€ / \mathrm{h} \cdot$ station $]$} & 0.4921 & $\begin{array}{l}\text { From the stations' investment cost in the electrical Bicing pilot } \\
\text { (1.94M€ for } 45 \text { stations), and considering a useful life of } 10 \text { years } \\
\text { [Ajuntament de Barcelona (2014); La Vanguardia (2014)]. }\end{array}$ \\
\hline & $\begin{array}{l}\text { Operative cost per electrical bike } \\
\text { trip }\end{array}$ & $\gamma_{o_{-} e b}$ & {$[€ /$ trip $]$} & 1.1061 & $\begin{array}{l}\text { The total operative cost of the electrical Bicing pilot (excluding } \\
\text { repositioning) was expected to be of } 2.2 \mathrm{M} € \text { and the total demand of } \\
2 \text { million trips for a } 3.5 \text { year period. [Ajuntament de Barcelona } \\
\text { (2014); La Vanguardia (2014)]. }\end{array}$ \\
\hline & $\begin{array}{l}\text { Usage time of a fully charged e- } \\
\text { bike }\end{array}$ & $T_{e b}$ & [hours] & 2.7 & $\begin{array}{l}\text { Computed as } D_{e b} / V_{e b} \text {, the ratio of the maximum distance covered } \\
\text { with a fully charged e-bike }(40 \mathrm{~km}) \text { over the average cycling speed in } \\
\text { urban environment }(15 \mathrm{~km} / \mathrm{h}) \text {. }\end{array}$ \\
\hline & $\begin{array}{l}\text { Time required to fully charge the e- } \\
\text { bike battery from empty }\end{array}$ & $T_{e b}^{\prime}$ & [hours] & 2 & [Ajuntament de Barcelona (2014)] \\
\hline
\end{tabular}

\subsubsection{Imbalance parameter estimation in the planning phase of a bike-sharing system}

3 From all the input parameters to the model, those related to the demand imbalance (i.e. $\Phi_{t}, \Phi_{q}, R_{t}$ and $R_{q}$ ) 4 are probably the most difficult ones to estimate in the planning phase of a bike-sharing system. While the average 5 demand density, $\lambda$, can be set as a policy goal (i.e. the demand level expected to materialize in the future and for

\footnotetext{
${ }^{5}$ Personal communication with operating agency representatives.
} 
1 which the system is going to be optimally designed, as discussed in Section 3.2.1), the imbalance parameters depend on the origin / destination structure of trips, which is difficult to anticipate.

Previous research on the asymmetry of bike sharing trips has shown that most of the users do not perform closed trip chains using the bike-sharing system (i.e. origin-destination + destination-origin trip chains). For example, [Zhao et al. (2015)] concluded, for a case study in Nanjin (China), that only $40 \%$ of the trips belong to closed trip chains. In addition, [Ehrgott et al. (2012); Winters et al. (2011)] show that even in closed trip chains, the selected routes are not necessarily symmetrical, because users tend to select routes away from traffic, pollution, debris and poor road maintenance. Cyclists also tend to avoid long steep sections in the selection of the best route, and this generally depends on the direction of the trip.

In spite of this, the spatial asymmetry in the individual usage of bike-sharing systems does not necessarily contribute to the system's imbalance. Note that the asymmetric behavior of one user could be balanced by the opposite behavior of another user. It is the generalized asymmetry of the O/D structure of trips which leads to imbalance situations. Two main factors have been identified to contribute to bike-sharing imbalance. First, the existence of segregated land-use urban patterns with a clearly asymmetrical temporal distribution of trips. For instance, the morning commute creates a scarcity of bicycles at residential areas and a surplus in activity and employment centers, or transit stations [Noland et al. (2016), Zhao et al. (2015)]. In the absence of rebalancing, such areas would be imbalanced and poorly served during most of the day, until the evening commute compensates the situation. In contrast, mixed land-use patterns contribute to a higher and more balanced bikesharing demand [Campbell et al. (2016)]. Second, the gradient in the terrain elevation also contributes to bikesharing imbalance, as users tend to avoid uphill trips [Ehrgott et al. (2012); Winters et al. (2011]. The higher areas in the bike-sharing service region tend to exhibit a scarcity of bicycles and poor service, contributing to lower demands [Faghih-Imani et al. (2017).

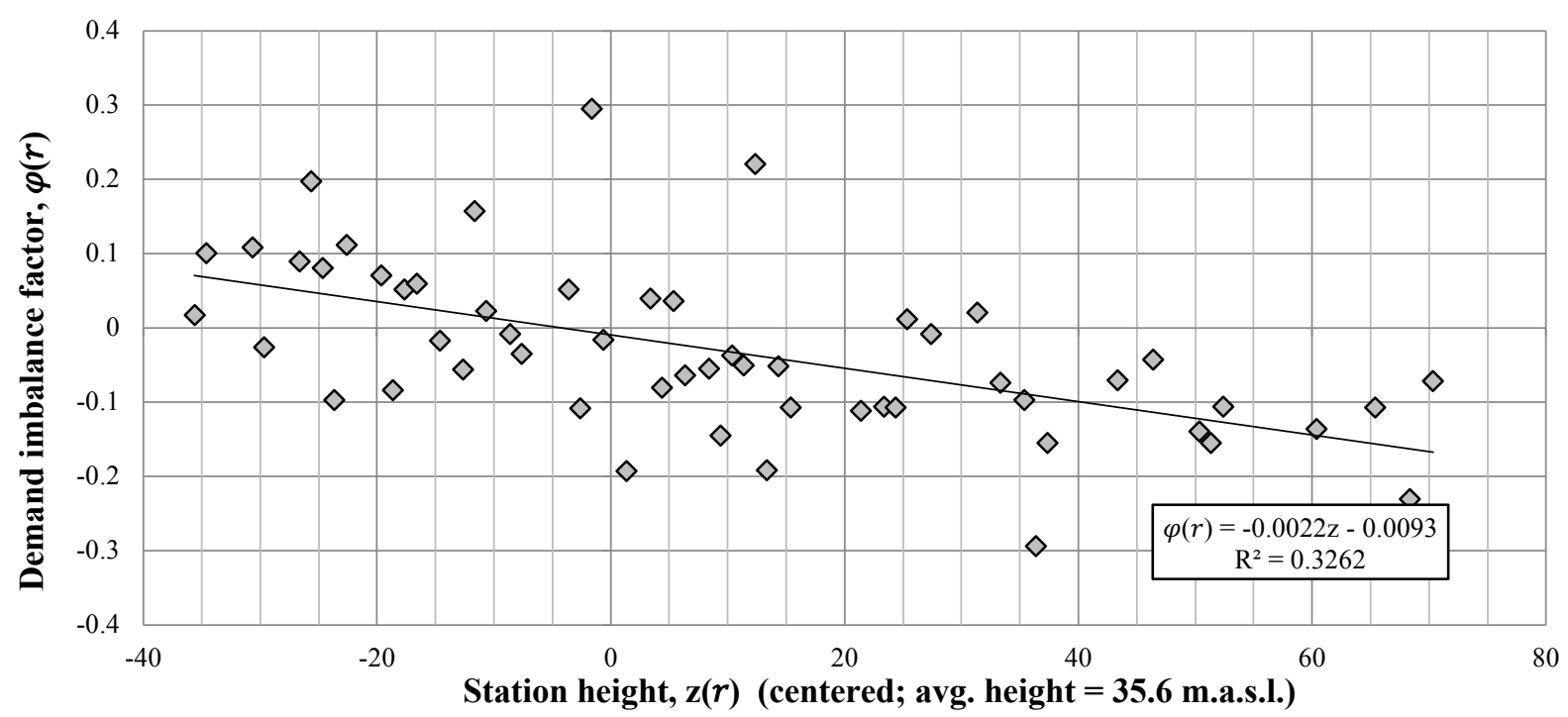

Fig. 2. Relationship between the demand imbalance factor and the stations' height. Note: Data extracted from the Bicing web service on May $7^{\text {th }} 2014$.

In such context, the distribution of stations' height can be used as a proxy to approximate the system's demand imbalance. Figure 2 shows the relationship between the stations' height, $z_{(r)}$, and their imbalance level, $\varphi_{(r)}$, for the Barcelona's Bicing system. Results corroborate that one the main causes of the system imbalance in bikesharing systems is that uphill trips are less desirable, so that bicycles tend to "precipitate" to lower elevation stations. Given this behavior, the height distribution across the service region could be used as a first approximation to estimate these imbalance parameters in the absence of more detailed data in the planning phase. 
1 For instance, one should expect higher imbalance levels for higher average slopes ${ }^{6}$ in the service region. In 2 addition, the area of the partition of $R$ with heights above the mean could be assimilated to $R_{q}$ (i.e. more requests than returns), and the complementary would be assimilated to $R_{t}$ (i.e. more returns than requests).

In flat cities, where the gradient in the terrain elevation is negligible, it is the land-use urban pattern what steers the system's demand imbalance. In such cases, the demand imbalance of bike-sharing systems will be similar to that of other on-demand transportation systems, such as taxi or car-sharing systems. The demand imbalance for these systems can then be used to estimate the imbalance parameters in the planning phase of bikesharing systems.

\subsection{Model validation}

The proposed optimization framework consists in minimizing a generalized cost function, composed of the main costs of a bike-sharing system (i.e. agency + users costs). In Section 3, these costs have been modeled in terms of the decision variables (i.e. subject to optimization) and some parameters. In addition, in order to reduce the number of degrees of freedom in the optimization (i.e. the number of independent decision variables), relationships between variables have been developed. This allowed establishing dependent decision variables ${ }^{7}$ (i.e. fleet size, $m$; number of parking slots, $M$; and number of repositioning teams) expressed as a function of independent design variables (i.e. density of stations, $\Delta$; repositioning period, $h$; and no-service probabilities, $P_{e}$ and $P_{f}$ ).

In order to validate the previous modelling approach two issues must be addressed. First, an accurate estimation of the model parameters; and second, the validation of the several models composing the generalized cost function. On the one hand, the parameters' estimation process has been presented in Table 2, noting that this is not free of difficulties, especially for those parameters which are subjective for each individual (e.g. different values and perceptions of time: $\beta, \beta_{\text {lost }}, t_{\text {lost } f}$ ). For such parameters, the validation of their estimations always involves a large degree of uncertainty [Wheat and Batley (2015)]. On the other hand, the validation of the models requires empirical observations of both, dependent and independent variables, in addition to the estimated parameters. This allows comparing the observed with the predicted dependent variables and establishing the models' accuracy. Note that the validation of the model does not require optimal designs, but just empirical observations from a particular case study. However, this validation is not always possible, because some of the variables are difficult to observe, especially those related to the user before entering the system. For instance, in the present models' validation emulating the Bicing system in Barcelona, the modeling of the access distance could not be validated, because observed values of the distance covered by users when accessing the system are not available. In contrast, results of the validation of the model for the bicycle fleet size, $m$, for the number of station-based parking slots, $M$, and for the repositioning model, are shown in Table 3 . It can be seen that the comparisons between observed and predicted values result in relative errors below 13\%, an indicator of the goodness of the model at this aggregate level.

\footnotetext{
${ }^{6}$ The average slope in the Barcelona Bicing service region is $1.5 \%$. The average slope is computed as $\frac{P_{90 t h}\left(z_{(r)}\right)-P_{10 t h}\left(z_{(r)}\right)}{\sqrt{R}}$, where $P_{i \text { th }}$ refers to the $i$ 'th percentile.

${ }^{7} m$ is just one possible selection as a dependent variable. This is consistent with the explicit formulation for $m$ (see Equation 15). In spite of this, any of the decision variables could be considered the dependent variable, and expressed in terms of the others with more or less complexity. For instance, it is particularly easy to obtain $P_{e}=f(\Delta, h, m)$.
} 
Table 3. Fleet size, station-based parking slots and repositioning models validation with Barcelona Bicing's observed data

\begin{tabular}{|c|c|c|c|c|c|}
\hline Variable description & Notation & Units & Model results ${ }^{*}$ & Observed data & Relative error \\
\hline Available fleet size & $m$ & [bikes] & 5622 & 5236 & $7.37 \%$ \\
\hline Average bike daily usage & - & [trips/bike $\cdot$ day] & 8.86 & 9.52 & $-6.87 \%$ \\
\hline Total number of parking slots & $M$ & [slots] & 10976 & 10246 & $7.12 \%$ \\
\hline Slots / fleet ratio & $M / m$ & [slots/bike] & 1.95 & 1.96 & $-0.23 \%$ \\
\hline Repositioning operations & - & [bikes/day] & 13621 & 13164 & $3.47 \%$ \\
\hline Number of repositioning teams & \#repo teams & - & 21 & 24 & $-12.5 \%$ \\
\hline
\end{tabular}

${ }^{*}$ Considering the Bicing's design variables: $\Delta=8.20\left[\right.$ stations $\left./ \mathrm{km}^{2}\right] ; h=8.39[\mathrm{~h}] ; P_{e}=0.1355 ; P_{f}=0.1247$; and all the parameters as in Table 2 .

\subsection{Optimization of the strategical design of a bike-sharing system: application to the Barcelona's Bicing}

Optimization of the system consists in the minimization of the generalized cost function so that optimal decision variables are obtained and some optimal key performance indicators can be derived. Different optimization scenarios are analyzed. First, a Lagrangian (i.e. unrestricted) optimization is performed. The Lagrangian scenario results in minimum overall costs, considering both user and agency costs. This global and unrestricted optimization depends on the unitary costs considered, which act as weighting factors for the several concepts in the generalized cost function (see Section 3.3). In particular, results depend on $\beta[€ / h]$, the users' value of time. The Lagrangian approach considers an average $\beta$, estimated for a particular society, so that the obtained solution is optimal from the social point of view.

However, in many cases the budget to deploy bike-sharing systems is limited, and generally not enough to provide this social optimum level of service. It is typical in these situations that policy makers define the minimum level of service the system should provide (i.e. a service standard). Given a limited budged, such restrictions are binding, and then the optimization consists in minimizing the agency costs while providing this minimum accepted level of service. These scenarios are referred to as "standards" optimization.

The defined standard's scenario imposes limited accessibility and availability of the service. Regarding accessibility, instead of minimizing users' access costs, the station density is set to $\Delta=8.20 \mathrm{stations} / \mathrm{km}^{2}$, corresponding to an average access distance of $175 \mathrm{~m}$ (see Equation 30). Regarding the availability, instead of minimizing no-service penalties, a default percentage of not served users is accepted. This is introduced in the model by fixing $P_{e}=0.1355$, meaning that, on average, $13.55 \%$ of the demand will not find any available bike within the desired sub-region. These service standards correspond to the current level of service offered by Barcelona's Bicing system.

In Tables 4 and 5, the results of the system optimization in the Lagrangian and standards scenarios are presented. Both, station-based and free-floating configurations are analyzed. Table 4 focuses on system design and Table 5 on system costs.

Results in the Lagrangian scenario show that the optimal level of service, from the social point of view, should be significantly higher than the current level of service offered by Barcelona's Bicing system. In this social optimum configuration, all user costs are reduced. This includes lower access distances to stations (i.e. higher station density), and extremely low probabilities of no-service, either because of empty or full stations (i.e. larger bicycle fleet and many more parking slots at stations). The optimal repositioning period is also shorter than the current one, implying higher reposition intensity. This, together with the increased decentralization (i.e. due to many more stations), implies that more repositioning trucks are necessary. Obviously, this improved level of service increases the agency cost (i.e. by $33 \%$ ), with the objective of achieving a greater reduction in user cost (i.e. $-71 \%$ ). Overall, the total (i.e. social) cost of the system is reduced by approximately $45 \%$. 
Table 4. Optimization results for the Barcelona's Bicing case study. Decision variables and system design.

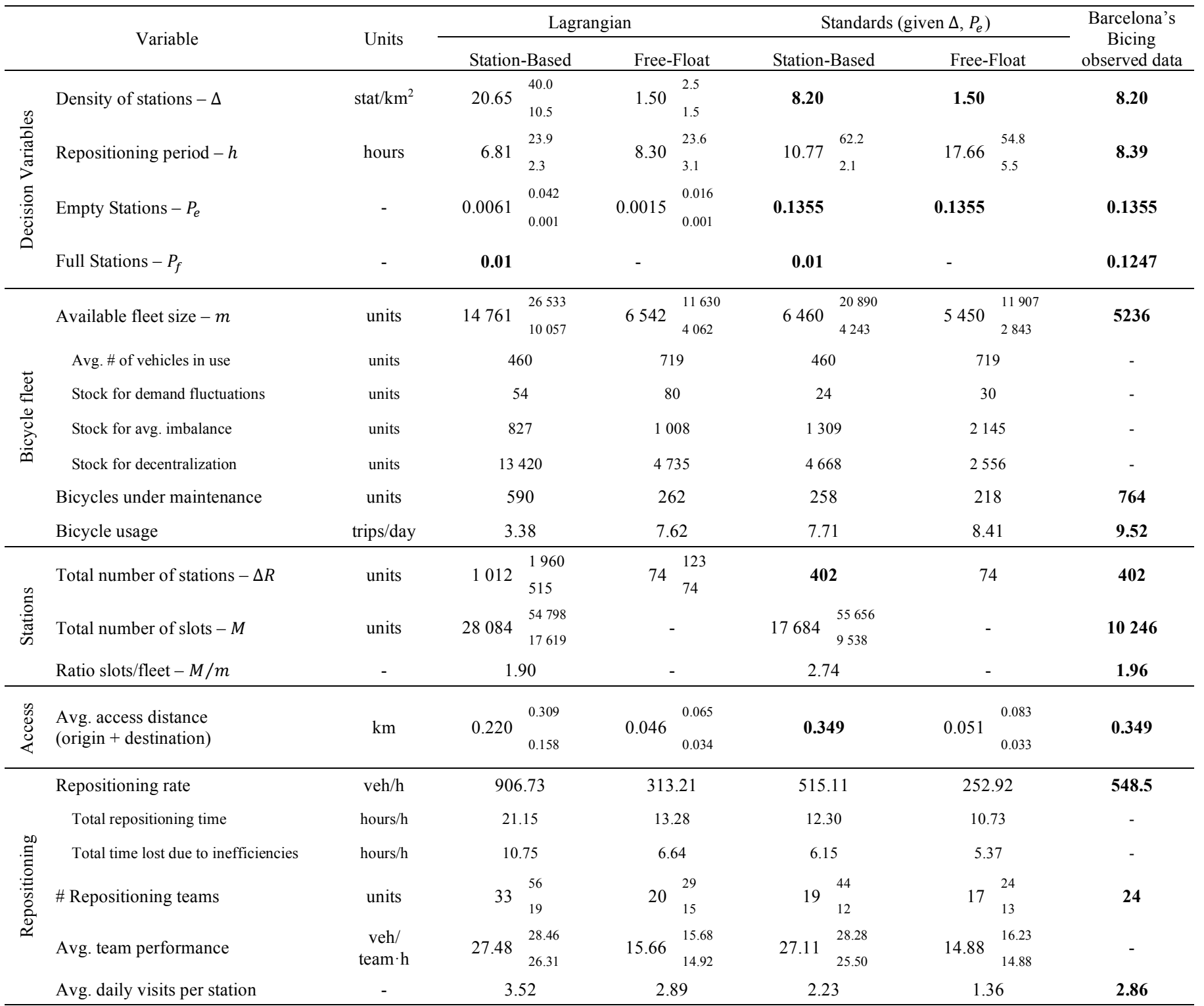

${ }^{*}$ Recall that the Bicing system serves an area $R=49 \mathrm{~km}^{2}$, with an average demand of $49832 \mathrm{trips} /$ day (i.e. $\lambda=42.37$ trips $/ \mathrm{h} \cdot \mathrm{km}{ }^{2}$ ), and an average imbalance $\Phi=$ 0.118 (see Table 2).

${ }^{* *}$ Values in bold represent inputs to the model and observed data. Model results are in non-bold characters.

${ }^{* * *}$ Upper and lower bounds are shown beside the optimal values for each variable. These bounds are defined as the maximum deviation from the optimal values so that the increase in total system cost is $<5 \%$, assuming that all other variables are kept at their optimal value. 
1 Table 5. Optimization results for Barcelona's Bicing case study. Costs:

\begin{tabular}{|c|c|c|c|c|c|c|c|}
\hline & \multirow{2}{*}{ Type of cost } & \multirow{2}{*}{ Units } & \multicolumn{2}{|c|}{ Lagrangian } & \multicolumn{2}{|c|}{ Standards (given $\Delta, P_{e}$ ) } & \multirow{2}{*}{$\begin{array}{l}\text { Barcelona's Bicing } \\
\text { current costs }\end{array}$} \\
\hline & & & Station-Based & Free-Float & Station-Based & Free-Float & \\
\hline \multirow{5}{*}{ 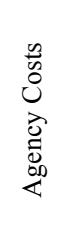 } & Infrastructure costs & $€ / \mathrm{h}$ & 758.93 & 359.16 & 319.46 & 299.20 & 294.24 \\
\hline & IC - Bikes & $€ / \mathrm{h}$ & 444.31 & 359.16 & 194.44 & 299.20 & 169.22 \\
\hline & IC - Stations & $€ / \mathrm{h}$ & 314.62 & - & 125.02 & - & 125.02 \\
\hline & Operation costs & $€ / \mathrm{h}$ & 1322.42 & 1322.42 & 1322.42 & 1322.42 & 1322.42 \\
\hline & Repositioning costs & $€ / \mathrm{h}$ & 424.12 & 303.48 & 281.21 & 245.32 & 310.70 \\
\hline \multirow{2}{*}{$\begin{array}{l}\dot{0} \\
\stackrel{0}{0} \\
\stackrel{0}{0}\end{array}$} & Access costs & $€ / h$ & 1447.06 & 301.58 & 2295.54 & 334.58 & 2295.54 \\
\hline & No service penalty & $€ / h$ & 245.61 & 13.83 & 1465.51 & 1277.02 & 3627.48 \\
\hline \multirow{4}{*}{ 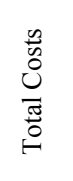 } & \multirow{2}{*}{ Total agency costs } & $€ / \mathrm{h}$ & 2573.06 & 1985.05 & 1923.10 & 1866.94 & 1927.35 \\
\hline & & M€/year & 22.54 & 17.39 & 16.85 & 16.35 & 16.88 \\
\hline & Total users' costs & $€ / \mathrm{h}$ & 1692.67 & 315.41 & 3761.04 & 1611.60 & 5923.02 \\
\hline & Total costs & $€ / \mathrm{h}$ & 4265.73 & 2300.46 & 5684.14 & 3478.54 & 7850.37 \\
\hline \multirow{3}{*}{ 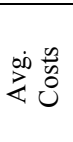 } & Generalized cost per trip ${ }^{1}$ & $€ /$ trip & 2.05 & 1.11 & 2.74 & 1.68 & 3.78 \\
\hline & Single Fare ${ }^{2}$ & $€ /$ trip & 1.24 & 0.96 & 0.93 & 0.90 & 0.93 \\
\hline & Annual Fare ${ }^{3}$ & $€ /$ year & 211.78 & 163.38 & 158.29 & 153.66 & $158.64^{4}$ \\
\hline
\end{tabular}

1 Average cost per trip, including agency and users' costs.

${ }^{2}$ Average agency cost per trip. This is equivalent to the fare users need to pay in the absence of subsidies.

${ }^{3}$ Assuming 147.3 trips/member year. This is the average annual usage per member in Barcelona's Bicing system.

${ }^{4}$ Currently, Barcelona's Bicing system is subsidized. Members pay only around $32 \%$ of this cost (i.e. $47.16 € /$ member $\left.\cdot y e a r\right)$

The standards scenario aims to optimize the system design by considering the current level of service offered by the Bicing system ${ }^{8}$. This is to minimize the agency cost by only optimizing the trade-off between the size of the bicycle fleet and the intensity of the repositioning operations. The results show that although the optimal design is achieved for a somewhat larger fleet and lower repositioning level, the overall benefits in total agency costs with respect to the current design are insignificant. This means that the actual design of the Bicing system in Barcelona is adequate, accepting the provided level of service as a standard. In spite of this, note that the noservice penalty at the destination, $P_{f}$, could be reduced by adding more parking slots at critical locations. An increase of $73 \%$ in the overall size of stations would reduce the probability of full stations from the current $12.5 \%$ to $1 \%$, almost eliminating this important penalty for users. This would significantly improve the level of service offered. The main cost of such decision would be the increase in urban space consumption. The distribution of urban space to different transportation modes and activities should be the object of a higher level of debate in the city planning.

In addition, results show that optimal designs are robust, as predicted by the generalized EOQ structure of the optimization problem. This means that deviations from the optimal values do not imply sharp increases in the overall costs. This can be observed from the results in Table 4, by realizing the significantly wide ranges of nearoptimal designs for which the overall cost does not increase more than $5 \%$ with respect to the optimal.

Finally, Tables 4 and 5 also allow comparing the station-based configuration, currently implemented in the Bicing system, with the free-floating alternative. The results show that free-floating configurations are able to provide a better level of service, in terms of a reduced access distance, with a smaller bicycle fleet and lower repositioning costs. The benefits of the free-floating configuration are more evident when the accessibility to the system needs to be high (i.e. Lagrangian scenario). This is because in the station-based configuration many stations are needed to achieve the required higher accessibility, and this also implies a larger bicycle fleet because

\footnotetext{
${ }^{8}$ The service standards considered include a maximum accepted access distance and a maximum no-service probability at the origin (i.e. due to empty stations).

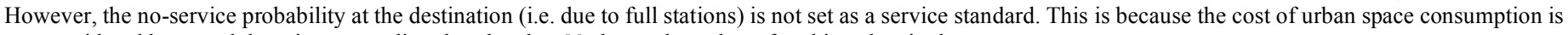
not considered here, and there is no cost directly related to $M$, the total number of parking slots in the system.
} 
1 of the higher decentralization. In contrast, when a low accessibility level suffices (e.g. in the standards scenario), 2 the benefits of free-floating diminish. This is because the penalties of station-based are less in this case, and 3 because a minimum number of sub-regions is also necessary in free-floating, to ensure, to some extent, a uniform 4 distribution of bicycles throughout the service region. This is why in the standards scenario the agency costs are 5 similar in station-based and free-floating configurations.

In spite of the clear benefit in the total costs of free-floating systems, they suffer from several important drawbacks. First, the accessibility of the system is given by the number of idle bicycles dispersed through the service region, and because this number changes with time, the access distance will vary significantly during the day. This means that during peak demand periods, the access distance will grow due to the lower bicycle availability. This variability in the level of service, and its deterioration in peak hours, penalizes the user perception of free-floating systems. In contrast, in station-based systems, the accessibility is given by the density of stations, which is constant with time. Second, in station-based systems the precise location of stations can be strategically selected in order to mitigate the average imbalance of the system by avoiding locating stations at the highest or lowest elevations in the service region. The ability to influence the origins and destinations of the trips with the station location is lost in free-floating systems, and therefore the average imbalance is expected to increase. This would imply an increase in the overall costs of the system (see Figure 4). Third, because bicycles lose the protection of stations when not used, and can be left in isolated zones inside the service region, they are more exposed to vandalism, deterioration and theft. This will probably reduce the useful life of bicycles, which is translated into a further increase in the prorated bicycle cost. And fourth, free-floating configurations are not suitable for the implementation of electric bike-sharing since the lack of stations complicates the battery recharging process.

\subsubsection{Optimization results considering electrical bicycles}

Tables 6 and 7 show the results of the system optimization in case of using electrical bikes in Barcelona's Bicing context. In order to facilitate the comparison, the previous results, using traditional mechanical bicycles (i.e. from Tables 4 and 5), are partially reproduced. Only station-based configurations are considered since this allows the battery recharging process. With respect to using mechanical bicycles, electrical bikes will imply higher infrastructure costs (of bicycles and stations), and also higher operative costs (see the electrical bicycle section of Table 2). In addition, the battery consumption restriction (see Equation 35) needs to be considered. The users' behavior, in terms of the overall demand and O/D structure of the trips, is assumed to not be affected by the adoption of electrical bicycles. This means, for instance, that the effects of electrical propulsion on the average duration of the trip $\left(\tau_{s}\right)$ and the average imbalance of the system $(\Phi)$ are not considered.

Results show that battery recharging does not represent an active restriction in electrical bike-sharing systems. This is because the minimum required fleet that allows a sufficient battery level to keep the system running is well below the optimal fleet required to account for demand fluctuations, system imbalance and decentralization. It can be concluded that station-based sharing systems are well posed for the implementation of electrical vehicles.

Secondly, it can be seen that agencies would confront the increase in the unitary cost of bicycles and stations (i.e. the infrastructure costs) by increasing the repositioning intensity (i.e. labor costs mainly). This implies a reduction of the bicycle fleet and station density, compensated by a reduction of the repositioning period. In addition, fewer bikes and stations also imply a reduction in the optimal level of service offered to users. In conclusion, the increase in the system's cost is shared between the operating agency and the users of the system. Therefore, if electrical bicycles do not confer additional benefits, which are not considered in the present model, there is no reason to implement them. The potential of electrical bike-sharing could be realized if electrical bicycles were able to modify user behavior. There is evidence that electrical bikes increase the attractiveness of cycling and reduce the aversion to both, distance and uphill trips [Jones et al. (2016), Fyhri and Fearnley (2015)]. In bike-sharing systems, this could imply an increase of demand $(\lambda)$, an increase of the average trip time $\left(\tau_{s}\right)$, and a reduction of the average imbalance $(\Phi)$ [Campbell et al. (2016)]. The reduction of the average imbalance 
1 directly implies a reduction in the total costs of the sharing system. In addition, the slight increase in average 2 costs per trip due to a higher service time could be largely compensated by the increase in demand due to the 3 existing economies of scale of bicycle sharing systems, as discussed in the next section. In conclusion, electrical 4 bicycles could modify the behavior of bike-sharing users so that the increase in infrastructure costs would be 5 compensated by a larger and more balanced demand.

Table 6. Optimization results for the electrical bicycle sharing system. Decision variables and system design.

\begin{tabular}{|c|c|c|c|c|c|c|}
\hline & \multirow{2}{*}{ Variable } & \multirow{2}{*}{ Units } & \multicolumn{2}{|c|}{ Lagrangian } & \multicolumn{2}{|c|}{ Standards (given $\Delta, P_{e}$ ) } \\
\hline & & & Traditional & Electrical & Traditional & Electrical \\
\hline \multirow{4}{*}{ 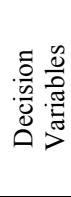 } & Density of stations $-\Delta$ & $\mathrm{stat} / \mathrm{km}^{2}$ & 20.65 & 13.44 & 8.20 & 8.20 \\
\hline & Repositioning period $-h$ & hours & 6.81 & 2.68 & 10.77 & 4.36 \\
\hline & Empty Stations $-P_{e}$ & - & 0.0061 & 0.0101 & 0.1355 & 0.1355 \\
\hline & Full Stations $-P_{f}$ & - & 0.01 & 0.01 & 0.01 & 0.01 \\
\hline \multirow{8}{*}{ 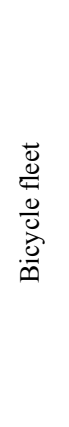 } & Available fleet size - $m$ & units & 14761 & 7129 & 6460 & 3982 \\
\hline & Avg. \# of vehicles in use & units & 460 & 460 & 460 & 460 \\
\hline & Stock for demand fluctuations & units & 54 & 50 & 24 & 24 \\
\hline & Stock for avg. imbalance & units & 827 & 326 & 1309 & 529 \\
\hline & Stock for decentralization & units & 13420 & 6294 & 4668 & 2969 \\
\hline & $\begin{array}{l}\text { Min. required fleet due to the } \\
\text { battery recharging restriction }\end{array}$ & units & - & 804 & - & 804 \\
\hline & Bicycles under maintenance & units & 590 & 285 & 258 & 159 \\
\hline & Bicycle usage & trips/day & 3.38 & 6.99 & 7.71 & 12.52 \\
\hline \multirow{3}{*}{ 节 } & Total number of stations $-\Delta R$ & units & 1012 & 658 & 402 & 402 \\
\hline & Total number of slots - $M$ & units & 28084 & 13809 & 17684 & 10836 \\
\hline & Ratio slots/fleet $-M / m$ & - & 1.90 & 1.94 & 2.74 & 2.72 \\
\hline 岁 & $\begin{array}{l}\text { Avg. access distance } \\
\text { (origin }+ \text { destination) }\end{array}$ & $\mathrm{km}$ & 0.220 & 0.273 & 0.349 & 0.349 \\
\hline \multirow{6}{*}{ 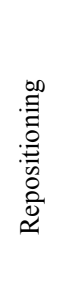 } & Repositioning rate & $\mathrm{veh} / \mathrm{h}$ & 906.73 & 1130.59 & 515.11 & 740.37 \\
\hline & Total repositioning time & hours $/ \mathrm{h}$ & 21.51 & 28.00 & 12.30 & 18.02 \\
\hline & Total time lost due to inefficiencies & hours $/ \mathrm{h}$ & 10.75 & 14.00 & 6.15 & 9.01 \\
\hline & \# Repositioning teams & units & 33 & 43 & 19 & 28 \\
\hline & Avg. team performance & $\begin{array}{l}\mathrm{veh} / \\
\text { team } \cdot \mathrm{h}\end{array}$ & 27.48 & 26.29 & 27.11 & 26.44 \\
\hline & Avg. daily visits per station & - & 3.25 & 8.94 & 2.23 & 5.51 \\
\hline
\end{tabular}

* Only station-based configurations are considered when using electrical bikes.

** These results consider Barcelona's Bicing system parameters shown in Table 2. In particular, a service area $R=49 \mathrm{~km}^{2}$, with an average demand of 49832 trips/day (i.e. $\lambda=42.37$ trips $/ \mathrm{h} \cdot \mathrm{km}^{2}$ ), and an average imbalance $\Phi=0.118$.

${ }^{* * *}$ Values in bold represent inputs to the model. Model results are in non-bold characters. 
Table 7. Optimization results for the electrical bicycle sharing system. Costs.

\begin{tabular}{|c|c|c|c|c|c|c|}
\hline & \multirow{2}{*}{ Type of cost } & \multirow{2}{*}{ Units } & \multicolumn{2}{|c|}{ Lagrangian } & \multicolumn{2}{|c|}{ Standards (given $\Delta, P_{e}$ ) } \\
\hline & & & Traditional & Electrical & Traditional & Electrical \\
\hline \multirow{5}{*}{ 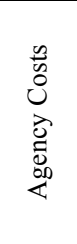 } & Infrastructure costs & $€ / h$ & 758.93 & 984.90 & 319.46 & 566.92 \\
\hline & IC - Bikes & $€ / \mathrm{h}$ & 444.31 & 660.90 & 194.44 & 369.10 \\
\hline & IC - Stations & $€ / \mathrm{h}$ & 314.62 & 324.00 & 125.02 & 197.82 \\
\hline & Operation costs & $€ / \mathrm{h}$ & 1322.42 & 3299.71 & 1322.42 & 3299.71 \\
\hline & Repositioning costs & $€ / \mathrm{h}$ & 424.12 & 640.09 & 281.21 & 411.90 \\
\hline \multirow{2}{*}{ 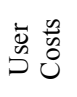 } & Access costs & $€ / \mathrm{h}$ & 1447.06 & 1793.71 & 2295.54 & 2295.54 \\
\hline & No service penalty & $€ / \mathrm{h}$ & 245.61 & 283.58 & 1465.51 & 1465.51 \\
\hline \multirow{4}{*}{ 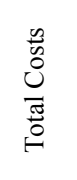 } & \multirow{2}{*}{ Total agency costs } & $€ / \mathrm{h}$ & 2573.06 & 4924.70 & 1923.10 & 4278.53 \\
\hline & & $\mathrm{M} € /$ year & 22.54 & 43.14 & 16.85 & 37.48 \\
\hline & Total users' costs & $€ / \mathrm{h}$ & 1692.67 & 2077.29 & 3761.04 & 3761.04 \\
\hline & Total costs & $€ / \mathrm{h}$ & 4265.73 & 7001.99 & 5684.14 & 8039.58 \\
\hline \multirow{3}{*}{ 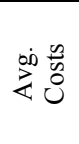 } & Generalized cost per trip ${ }^{1}$ & $€ /$ trip & 2.05 & 3.37 & 2.74 & 3.87 \\
\hline & Single Fare ${ }^{2}$ & $€ /$ trip & 1.24 & 2.37 & 0.93 & 2.06 \\
\hline & Annual Fare ${ }^{3}$ & $€ /$ year & 211.78 & 405.34 & 158.29 & 352.16 \\
\hline
\end{tabular}

* These results consider Barcelona's Bicing cost parameters shown in Table 2.

${ }^{1}$ Average cost per trip, including agency and user costs.

${ }^{2}$ Average agency cost per trip. This is equivalent to the fare users need to pay in the absence of subsidies.

${ }^{3}$ Assuming 147.3 trips/member year. This is the average annual usage per member in Barcelona's Bicing system.

\subsection{Sensitivity analysis and generalized results}

A sensitivity analysis of the model, with respect to the input parameters that can significantly vary between different implementations or that can evolve with time, allows extending the previous results and obtaining some general conclusions and recommendations for the planning of bicycle sharing systems. All the analyses in this section refer to the optimization results obtained in the Lagrangian scenario (i.e. min. total costs).
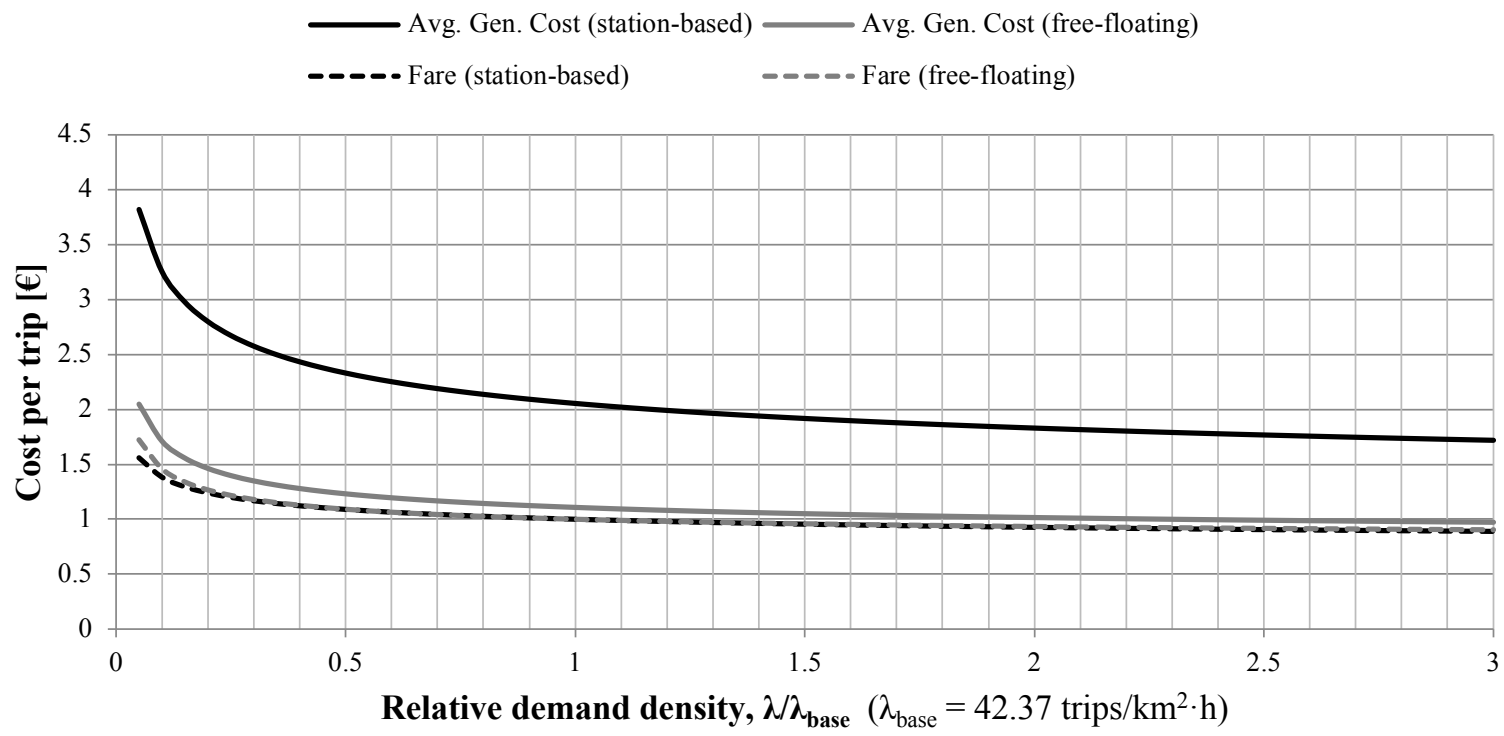
Figure 3 shows that bicycle sharing systems exhibit economies of scale. This means that the average cost per trip is reduced with an increase of the overall demand of the system. Economies of scale are due to the higher utilization of bikes and stations (i.e. pooling effect). Repositioning and operative costs are proportional to demand and do not contribute to the economies of scale. Economies of scale are particularly intense for low demand. For average demand densities lower than 20 trips $/ \mathrm{km}^{2} \cdot \mathrm{h}$, the average cost per trip grows rapidly, and the viability and competitiveness of bicycle sharing systems is jeopardized. In contrast, the sensitivity of the system design variables for higher demand is lower but still significant. As an example, if the demand increases by a factor of 3 (with respect to the base demand of Barcelona's Bicing system of $\lambda=42.37 \mathrm{trips} / \mathrm{km}^{2} \cdot \mathrm{h}$ ) the fleet size and the station density is multiplied only by 2 . Overall, the total costs increase by a factor of 2.55 . This results in a reduction of the average costs by a factor of 0.85 . Economies of scale are very similar in stationbased and free-floating configurations. From Figure 3 it can also be seen that the average generalized cost of free-floating systems is lower than the station-based equivalent for all demand levels. This is due to a better average level of service in the free-floating configuration (i.e. lower user costs) for the same agency costs.

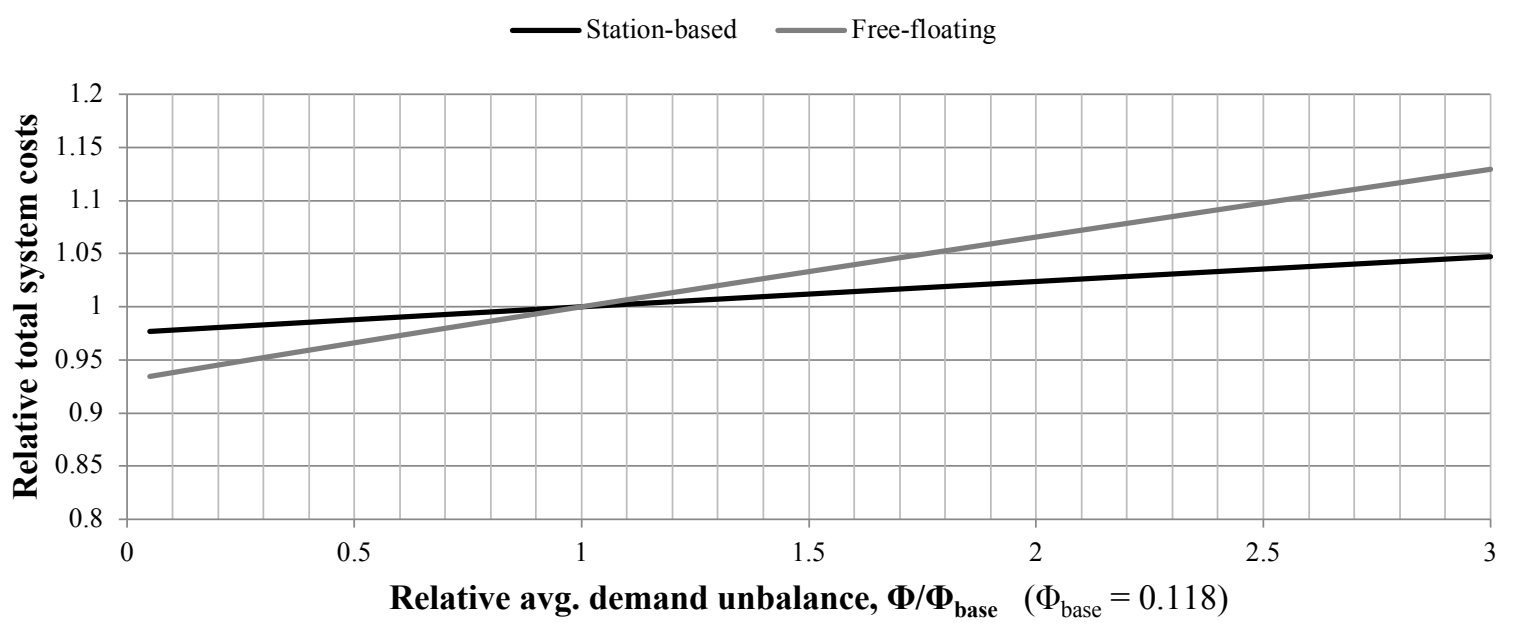

Fig. 4. Effects of the average demand imbalance in total costs of bike-sharing systems

The effect of the average demand imbalance, $\Phi$, on the costs of bike-sharing systems is analyzed in Figure 3 . It is shown that system costs increase with $\Phi$. This is because more bicycles and more repositioning are needed to compensate for the higher system imbalance. The elasticity of total costs with respect to $\Phi$ is 0.02 for stationbased configurations and 0.07 for free-floating systems, for all $\Phi$ levels (i.e. the slope of the linear relationship between the relative increase in $\Phi$ and the relative increase in total costs). This means that free-floating configurations are more sensitive to the increase of $\Phi$ than their station-based equivalents. Taking into account that free-floating systems tend to higher $\Phi$ values because the location of the stations cannot help in modulating the demand, the increase in costs due to this factor in free-floating systems is more likely.

Next, Figure 5 analyzes the effects of the acquisition cost of bikes on the design of public bike-sharing systems. This shows the high elasticity of the fleet size for low bicycle acquisition costs. This analysis is especially relevant since there is an extremely high variability in the reported acquisition cost of bicycles. While for the Barcelona Bicing system bikes cost $400 €$ each [López (2009)] and the first generation of bikes with enhanced ICT capabilities in order to be used in free-floating systems costs $786 €$ each [Lee (2017)], today, the bicycle costs reported for the huge Chinese free-floating implementations are as low as $40 € /$ bike [Lee (2017)]. With these costs, which represent $10 \%$ or less of the considered cost for bicycles, the size of the fleet would be multiplied by a factor of 4 or even more. The increase of the bicycle fleet implies a reduction of the repositioning intensity. This means that if bicycle costs are very low (especially with respect to the repositioning costs) systems will tend to have huge bike fleets and very little repositioning. This is, for instance, what happened in the Chinese 
1 free-floating implementations. Such large bike fleets create problems in the urban environment because of 2 bicycles clogging pedestrian walkways and green zones. The conclusion is that bicycle parking regulations 3 should be addressed when implementing free-floating bike-sharing systems. In addition, in such contexts a 4 maximum fleet size could also be established. This would force the operating agency to consider repositioning 5 operations.

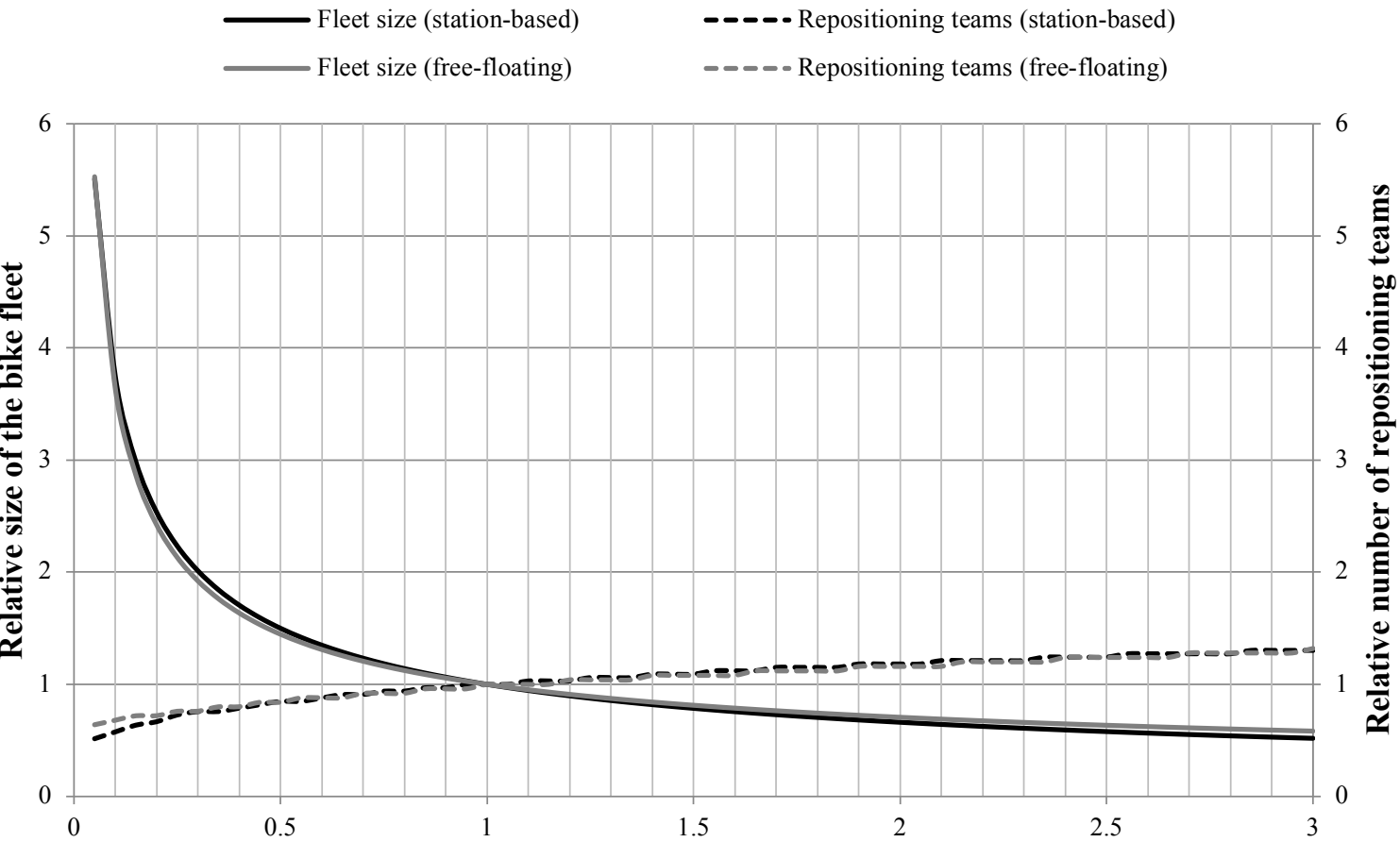

Relative bicycle unitary cost

(base: Station-based $=400 € /$ bike; Free-floating $=786 € /$ bike )

Fig. 5. Effects of bicycle unitary costs on the size of the bike fleet and repositioning intensity (station-based configuration).

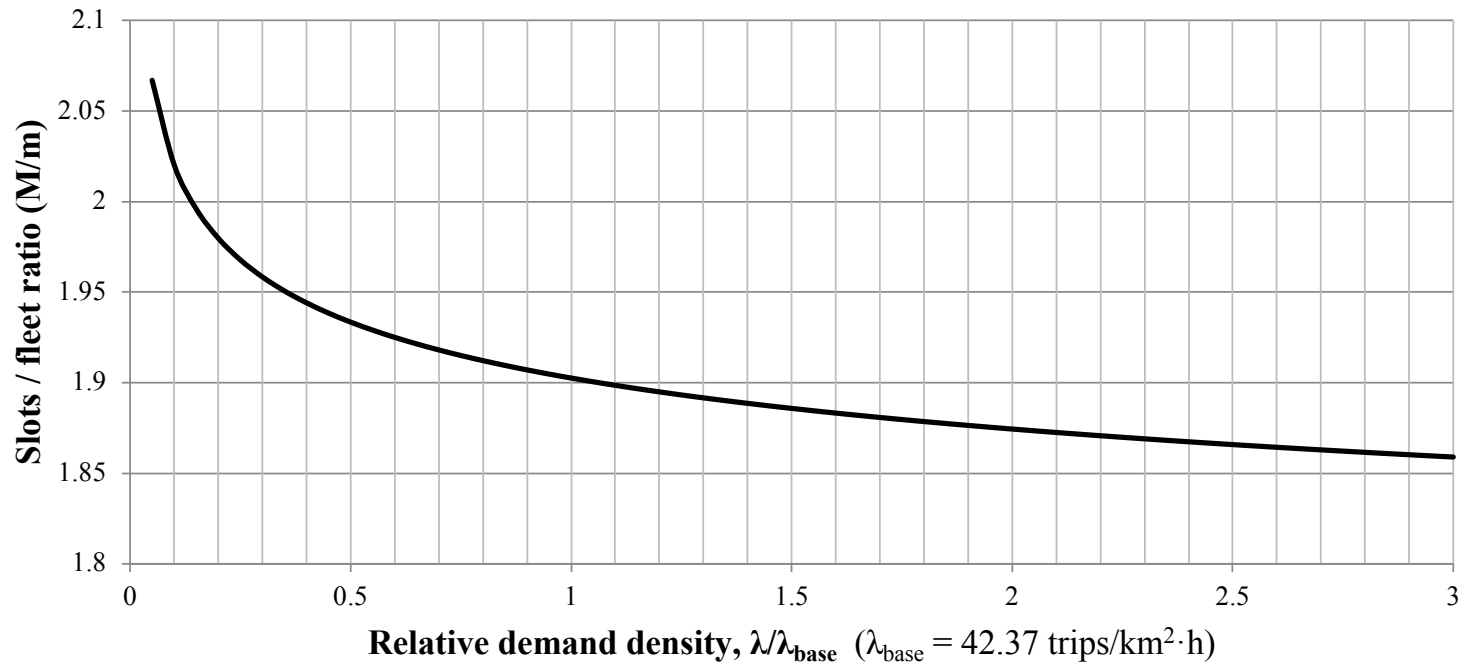

Fig. 6. Sensitivity of the parking slots to bicycles ratio $(M / m)$ in optimal station-based bicycle sharing systems. Note: A probability of full stations $P_{f}=0.01$ is considered. 
Finally, Figure 6 analyzes the parking slots to bicycles ratio, $M / m$. This ratio is of much interest when planning station-based bike-sharing systems, as it is frequently used to determine the overall capacity of stations in the system. This ratio determines the average probability of full stations at the destination. Results show that the optimal ratio is quite stable for different demand levels. Values range from 1.85 to 2.05 , for a $1 \%$ probability of full stations. The lower values are obtained for higher demands. As a general guideline, $M / m=1.9$ would be acceptable for a wide range of demand levels where bike-sharing systems are viable. This recommendation is valid given the social optimum bike fleet, $m$ (i.e. from the Lagrangian optimization). In standards scenarios, where the bike fleet can be sub-optimal (e.g. due to a higher accepted probability of empty stations, $P_{e}$ ), $M / m$ ratios of around 1.9 would lead to an equally sub-optimal overall number of parking slots, $M$. In such a case, this ratio would imply a similar accepted probability of full stations, $P_{f}$. If the consumption of urban space is not critical, larger $M / m$ ratios are encouraged in these scenarios (e.g. $M / m=2.74$ for Barcelona's Bicing standards scenario).

\section{Conclusions and further research}

The continuous approximations model for bicycle sharing systems presented in this paper allows obtaining optimal system designs, in terms of the size of bicycle fleet, the number of stations, the total number of parking slots and the required rebalancing intensity. The model also allows comparing station-based with free-floating configurations and assessing the battery recharging restriction when using electrical bikes. The proposed analytical model is validated against Barcelona's Bicing system, obtaining relative errors below $13 \%$ in the design variables and performance indicators.

For the particular case of Barcelona's Bicing, the optimization shows that the current level of service offered is sub-optimal from the social point of view. This is considering the trade-off between user and agency costs, where user costs are obtained from the monetization of the access time and penalties due to empty or full stations. The results show that by increasing the level of service, the benefits for users largely compensate for the increase in agency costs. In spite of this, if the current Bicing level of service is accepted as a standard, for instance due to budget limitations, the actual system design is adequate in terms of the number of bicycles, stations and repositioning level. Nevertheless, the possibility of full stations could be virtually eliminated by adding more parking slots. 1.9 parking slots per bicycle are recommended in optimal configurations. However, if the system design is sub-optimal, with a limited level of service and bicycle fleet, keeping this ratio implies an equally suboptimal probability of full stations.

Generalizing the results, it can be said that optimal designs are robust for all the inputs of the model, in the sense that the results exhibit small elasticities in all unitary costs and technological parameters. Also, deviations from the optimal system design do not imply a large increase in the total system cost. In spite of this, the sensitivity of the model has been analyzed with respect to those inputs whose value might vary largely in different implementations. The average demand density is one of such inputs. It is proven that economies of scale exist in bicycle sharing systems. The average cost per trip is reduced with growing demand. For low demand levels (e.g. less than 20 trips $/ \mathrm{km}^{2} \cdot \mathrm{h}$ ) the average cost per trip increases significantly and the viability and potential of bikesharing systems is compromised.

The acquisition cost of bikes could also vary largely between different implementations and this significantly affects the trade-off between the size of the bike fleet and the repositioning level. Especially if bicycle cost is very low, the size of the fleet can greatly increase. Actually, this happened in the recent Chinese implementations of free-floating bike-sharing systems, where the reported cost of bikes is as low as $40 € /$ bike. Huge fleets are spread throughout cities while repositioning operations are kept to a minimum, if not inexistent. This creates problems of bicycle accumulation in the central areas of these cities. The recommendation in this context should be to address bicycle parking policies and analyze the possibility of imposing a maximum fleet size for bikesharing systems. This would force the operating agency to reposition bicycles in order to maintain the required level of service. This situation brings into question the suitability of free-floating bike-sharing configurations. 
1 Free-floating can provide a better average level of service with lower agency costs, in comparison to an 2 equivalent station-based configuration. This benefit is particularly significant when the access distance to 3 bicycles is desired to be especially short. However, free-floating configurations may imply other problems: 4 bicycles tend to clog up city centers; the level of service deteriorates during peak hours (i.e. longer walking distance to bikes) because of a reduction in the number of idle bicycles; bicycles are more exposed to theft and vandalism and their useful life is reduced; and the average imbalance of the system could increase in the absence of the station regulatory effect. All these effects would eventually increase system costs. For instance, note that system costs increase with the average demand imbalance, and elasticity is higher for free-floating than for station-based systems.

Free-floating bike-sharing configurations are also not suitable for the implementation of e-bikes, unless solar battery recharging technology is developed at a competitive cost for e-bikes. Meanwhile, electrical bike-sharing will need to rely on recharging stations. The results obtained in this paper show that in station-based systems, the usage of electrical bikes does not imply an increase of the bike fleet due to battery recharging restrictions. The possibility of mixed systems (i.e. free-floating but with some stations to allow battery recharging) is not analyzed here and it is left for further research. In this mixed configuration, repositioning movements could not only be used to rebalance bicycle locations, but also to rebalance the available battery levels in the system. In general, the usage of electric bicycles implies an increase in the infrastructure and operative costs of bike-sharing systems. In spite of this, their potential resides in their ability for increasing cycling attractiveness and reducing users' aversion to uphill trips. These would be translated into higher and more balanced demands, contributing to compensating for the increase in cost when using electrical bikes.

Actually, user behavior regarding bicycle sharing systems is a topic of rising interest [Abolhassani, et al. (2019); Godavarthy and Rahim Taleqani (2017); Mattson and Godavarthy (2017); Reynaud et al. (2018)] and still requiring further research. This means not only developing endogenous demand models able to estimate bike-sharing demand for a given level of service, or to assess the effects on demand of using electrical bicycles, but also to investigate pricing policies to promote self-rebalancing trips or to assess the potential benefits and penalties of allowing bicycle reservations.

We conclude that the CA model presented in this paper and its results provide valuable insights and a better understanding of bicycle sharing systems. In spite of this, it is necessary to highlight that the simplifications made in order to formulate a parsimonious model (e.g. uniform demand, average imbalance, average repositioning) imply that the obtained results should be considered only in aggregate terms. This means that the proposed model could be used in order to obtain a first approach in the design of bicycle sharing systems (i.e. in the planning phase). Other model types could be used for the fine tuning of this first approach solution in the tactical and operational phases. For instance, station locations and their specific size and optimal inventory levels could be determined using discrete methods from the operations research field (e.g. solution methods for the facility location problem), with the inputs of more or less detailed O/D demands. Also, due to the importance of relocating strategies in overall costs, these should be addressed in detail in the operational phase of the system. This implies designing strategies to efficiently solve the dynamic "transportation problem", also a problem with a long tradition in the field of operations research. In this context, the proposed CA model should not only be considered as a fast alternative to obtain approximate solutions, but could also be integrated into these exact and heuristic solution approaches.

Finally, the operational optimization of sharing systems can also be addressed using simulation-optimization techniques. Bicycle sharing operations could be emulated and the simulation could be fed with real-time information in order to obtain a real-time management tool. At this operational level the CA approach can also play a role, increasing the responsiveness of the system in a dynamic decision-making environment with respect to using only discrete exact models. 


\section{Acknowledgements}

The authors acknowledge the work of Anna Llopis in the early stage of this research. Regarding the data for the case study, this would not have been possible without the open data portal initiative of the Barcelona city council, which includes the Bicing system. The comments of anonymous reviewers, which have helped in improving the paper, are also gratefully acknowledged.

\section{References}

Abolhassani, L., A. P. Afghari and H. M. Borzadaran. (2019). Public preferences towards bicycle sharing system in developing countries: The case of Mashhad, Iran.

Sustainable Cities and Society 44, 763-773.

Ajuntament de Barcelona. (2007). Estudi d'hàbits de mobilitat dels usuaris del Bicing. Market Aad. (in Catalan).

Ajuntament de Barcelona. (2014). Projecte Bicing elèctric 2015-2017. (in Catalan).

Ajuntament de Barcelona. (2016). Dades bàsiques de Mobilitat 2015. (in Catalan).

Alonso, M., B. Estapé, J. Fernández, R. Núñez-Romero, D. Sanz and X. Vallés. (2015). Gestión del Bicing BCN: Un algoritmo para un equilibrio sostenible. $3^{a}$ Conferencia \& Exposición BioEconomic. Tarragona. 6 May 2015. (In Spanish)

Alvarez-Valdes, R., J.M. Belenguer, E. Benavent, J.D. Bermudez, F. Muñoz, E. Vercher and F. Verdejo. (2016) Optimizing the level of service quality of a bike-sharing system. Omega 62, 163-175.

Ansari, S., Basdere, M., Li, X., Ouyang, Y., and Smilowitz, K. (2017). Advancements in continuous approximation models for logistics and transportation systems: 1996-2016. Transportation Research Part B 107, 229-252.

Asensio, J., and A. Matas. (2008). Commuters' valuation of travel time variability. Transport. Res. Part E 44 (6), 1074-1085.

Ashqar, H.I., M. Elhenawy and H.A. Rakha. (2019). Modeling bike counts in a bike-sharing system considering the effect of weather conditions. Case Studies on Transport Policy 7(2), 261-268.

Barcelona's Bicing website (www.bicing.cat). Accessed July 2017.

Benchimol, M., P. Benchimol, B. Chappert, A. de la Taille, F. Laroche, F. Meunier and L. Robinet. (2011). Balancing the stations of a self-service "bike hire" system. RAIRO-Operations Research 45(1), 37-61.

Bike-sharing World Map. (2019). MetroBike, LLC. Washington, D.C., USA. www.bikesharingmap.com. Accessed in June 2019.

Caggiani, L. and M. A. Ottomanelli. (2013). A dynamic simulation based model for optimal fleet repositioning in bike sharing systems. Procedia-Social and Behavioral Sciences 87, 203-210.

Caggiani, L., R. Camporeale, M. Ottomanelli and W. Y. Szeto. (2018). A modeling framework for the dynamic management of free-floating bike-sharing systems. Transportation Research Part C: Emerging Technologies 87, 159-182.

Campbell, J. F., A. T. Ernst and M. Krishnamoorthy. (2002). Hub location problems. In: Drezner, Z., Hamacher, H. (Eds.), Facility Location: Applications and Theory. Springer-Verlag, New York, 373-406.

Campbell, A.A., C.R. Cherry, M.S. Ryerson, X. Yang. (2016). Factors influencing the choice of shared bicycles and shared electric bikes in Beijing. Transportation Research Part C 67, 399-414.

Cao, Y. and D. Shen. (2019). Contribution of shared bikes to carbon dioxide emission reduction and the economy in Beijing. Sustainable Cities and Society $51,101749$. Çelebi, D., A. Yörüsün, and H. Işı1k. (2018). Bicycle sharing system design with capacity allocations. Transportation Research Part B: Methodological, 114, 86-98.

Chemla, D., F. Meunier and R. Wolfler Calvo. (2013). Bike sharing systems: solving the static rebalancing problem. Discrete Optimization 10(2), $120-146$.

Contardo, C., C. Morency and L. M. Rousseau. (2012). Balancing a dynamic public bike-sharing system. Technical report CIRRELT-2012-09. CIRRELT, Université de Montréal, Montréal,Canada.

Daganzo, C. F. and G. F. Newell. (1986). Configuration of physical distribution networks. Networks 16 (2), 113-132.

Daganzo, C. F. and K. R. Smilowitz. (2004). Bounds and approximations for the transportation problem of linear programming and other scalable network problems. Transportation Science 38 (3), 343-356.

Daganzo, C.F. (2005). Logistics Systems Analysis. Springer.

Daganzo, C.F. (2010). Public Transportation Systems: Basic Principles of System Design, Operations Planning and Real-Time Control. Institute of Transportation Studies, University of California, Berkeley.

Datner, S., T. Raviv, M. Tzur and D. Chemla. (2017). Setting Inventory Levels in a Bike Sharing Network. Transportation Science 53(1), 62-76.

Dell'Amico, M., E. Hadjicostantinou, M. Iori and S. Novellani. (2014). The bike sharing rebalancing problem: mathematical formulations and benchmark instances. Omega 45, 7-19.

DeMaio, P. (2009). Bike-sharing: History, impacts, models of provision, and future. Journal of Public Transportation 12, 41-56.

Ehrgott, M., J.Y.T. Wang, A. Raith and C. Van Houtte. (2012). A bi-objective cyclist route choice model. Transportation Research Part A 46(4), $652-663$.

Faghih-Imania, A., R. Hampshireb, L. Marlac and N. Elurud. (2017). An empirical analysis of bike sharing usage and rebalancing: Evidence from Barcelona and Seville. Transportation Research Part A 97, 177-191.

Frade, I. and A. Ribeiro. (2015). Bike-sharing stations: A maximal covering location approach. Transportation Research Part A 82, $216-227$.

Fyhri, A., N. Fearnley. (2015). Effects of e-bikes on bicycle use and mode share. Transportation Research Part D 36, 45-52.

García-Palomares, J.C., J. Gutiérrez and M. Latorre. (2012). Optimizing the location of stations in bike-sharing programs: a GIS approach. Applied Geography 35, 235246.

Godavarthy, R. P. and A. Rahim Taleqani. (2017). Winter bikesharing in US: User willingness, and operator's challenges and best practices. Sustainable Cities and Society 30, 254-262.

Heinen, E., B. Wee and K. Maat. (2010). Commuting by bicycle: An overview of the literature. Transport Reviews 30(1), 59-96.

IDAE. (2007). Guía metodológica para la implantación de sistemas de bicicletas públicas en España. Madrid: Instituto para la Diversificación y Ahorro de la Energía. In Spanish.

Jain, D. and G. Tiwari. (2016). How the present would have looked like? Impact of nonmotorized transport and public transport infrastructure on travel behavior, energy consumption and CO2 emissions - Delhi, Pune and Patna. Sustainable Cities and Society 22, 1-10. 


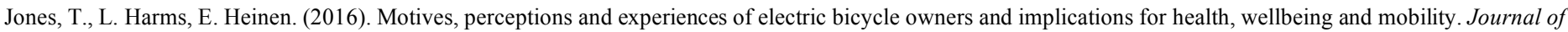
Transport Geography, 53, 41-49.

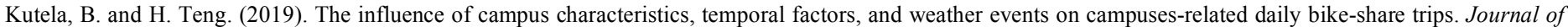
Transport Geography 78, 160-169.

La Vanguardia. (2014). Barcelona implantará el Bicing eléctrico con 300 bicicletas a finales de año. Press release.

Larson, R. C. and A. R. Odoni. (1981). Urban operations research. Prentice-Hall.

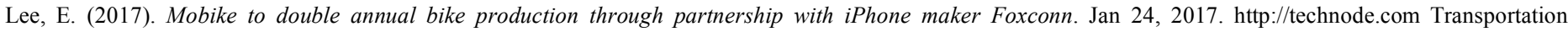
(http://technode.com/category/industries-and-verticals/transportation/), China (http://technode.com/category/location/china/)

Li, Y., W.Y. Szeto, J. Long and C.S. Shui. (2016a). A multiple type bike repositioning problem. Transportation Research Part B 90, $263-278$.

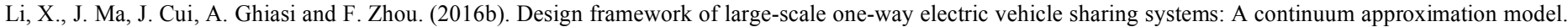
Transportation Research Part B 88, 21-45.

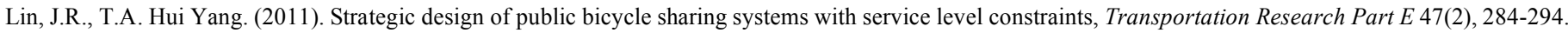

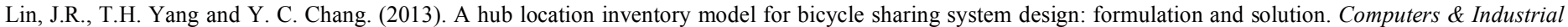
Engineering 65, 77-86.

Little, J. D. C. (1961). A proof for the queuing formula: $\mathrm{L}=\lambda \cdot \mathrm{W}$. Operations Research 9(3), pp. 383-387.

López, A. (2009). Bicing, el transporte público individual de Barcelona. B:SM, Ajuntament de Barcelona. (in Spanish).

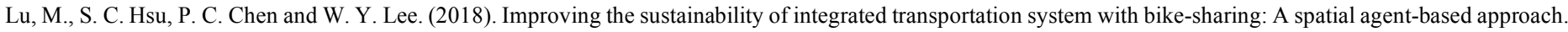
Sustainable Cities and Society 41, 44-51.

Maister, D. H. (1984). The psychology of waiting lines. Harvard Business School.

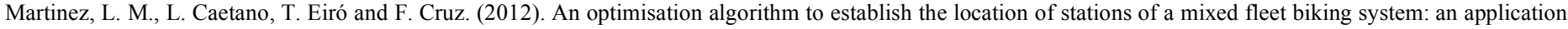
to the City of Lisbon. Procedia - Social and Behavioral Sciences 54, 513-524.

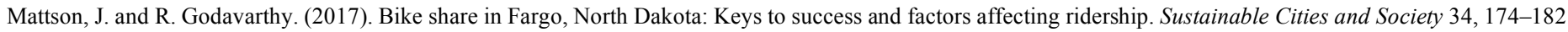

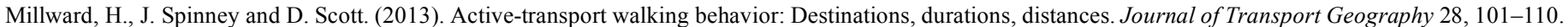

Nair, R. and E. Miller-Hooks. (2011). Fleet management for vehicle sharing operations. Transportation Science 45(4), 524-540.

Noland, R., M. Smart and Z. Guo. (2016). Bikeshare trip generation in New York City. Transportation Research Part A 94, $164-181$.

Pal, A. and Y. Zhang. (2017). Free-floating bike sharing: Solving real-life large-scale static rebalancing problems. Transportation Research Part $C$ 80, 92-116.

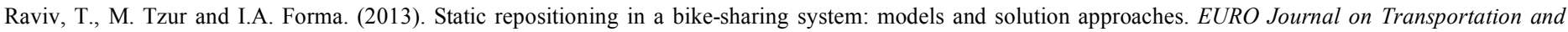
Logistics 2(3), 187-229.

Reiss, S. and K. Bogenberger. (2016). Validation of a relocation strategy for Munich's bike sharing system. Transportation Research Procedia 19, 341 - 349.

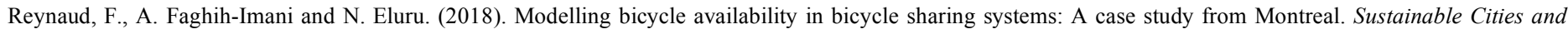
Society $43,32-40$

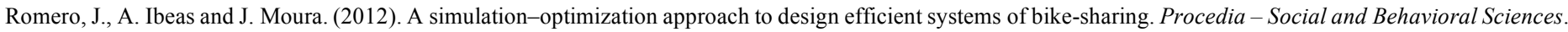
$54,646-655$.

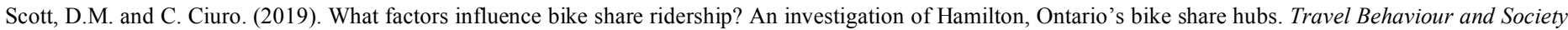
$16,50-58$.

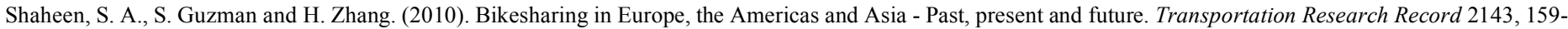
167.

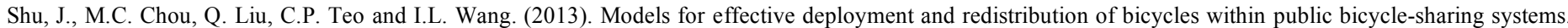
Operations Research 61:6, 1346-1359.

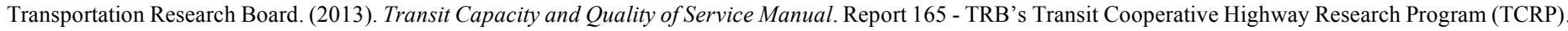
Third Edition.

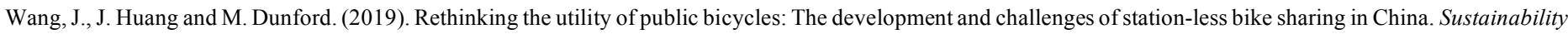
$11,1539$.

Wheat, P., R. Batley. (2015). Quantifying and decomposing the uncertainty in appraisal value of travel time savings. Transport Policy 44, 134-142.

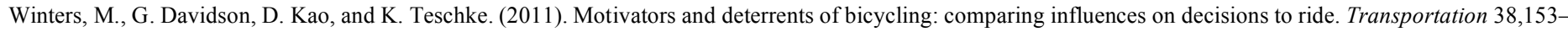
168.

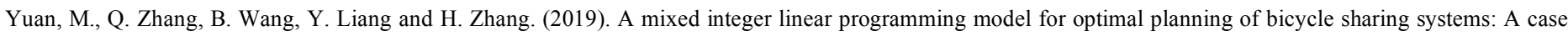
study in Beijing. Sustainable Cities and Society 47, 101515.

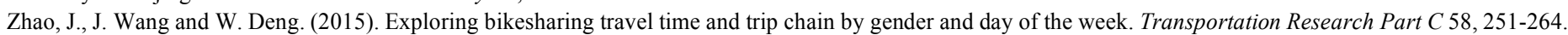

